Urban Flood Damage Reduction and Channel Restoration Demonstration Program for Arid and Semi-Arid Regions

\title{
Hydraulic Design of Channels Conveying Supercritical Flow
}

Richard L. Stockstill

July 2006 


\title{
Hydraulic Design of Channels Conveying Supercritical Flow
}

\author{
Richard L. Stockstill \\ Coastal and Hydraulics Laboratory \\ U.S. Army Engineer Research and Development Center \\ 3909 Halls Ferry Road \\ Vicksburg, MS 39180-6199
}

Final report

Approved for public release; distribution is unlimited. 


\begin{abstract}
This is a review of the Hydrologic Criteria and Drainage Design Manual (Clark County Regional Flood Control District 1999) of the Clark County Regional Flood Control District (CCRFCD). Areas of needed research relative to channels conveying supercritical flow and corresponding channel appurtenances have been identified.
\end{abstract}

The extension of features common to supercritical channel flow is presented. A case is made that extension of hydraulic design guidance of supercritical confluences (trapezoidal channels and laterals from storm drains), extensions to bridge piers, and access ramps for trapezoidal channels is needed.

DISCLAIMER: The contents of this report are not to be used for advertising, publication, or promotional purposes. Citation of trade names does not constitute an official endorsement or approval of the use of such commercial products. All product names and trademarks cited are the property of their respective owners. The findings of this report are not to be construed as an official Department of the Army position unless so designated by other authorized documents. 


\section{Contents}

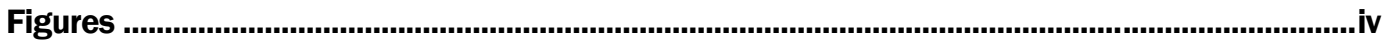

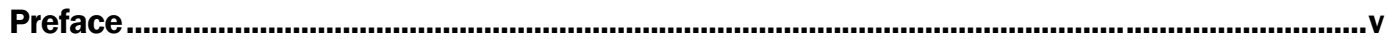

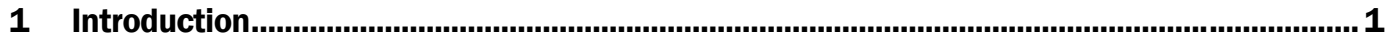

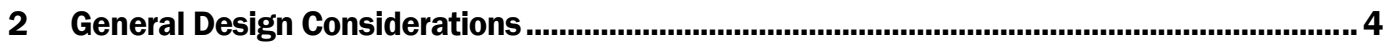

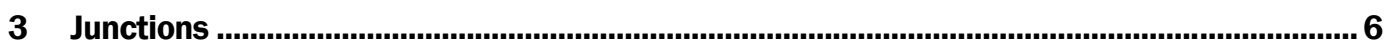

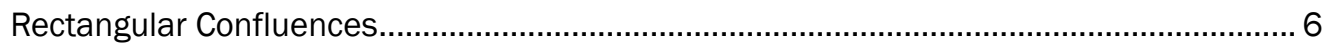

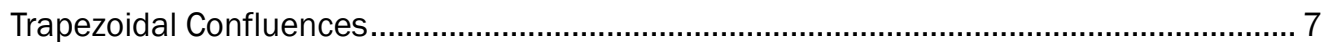

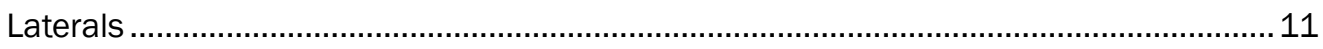

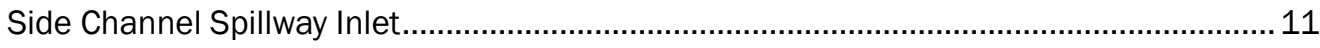

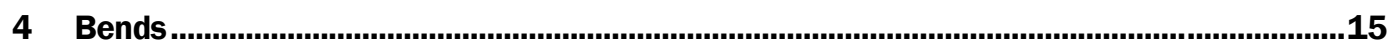

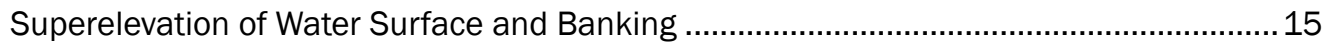

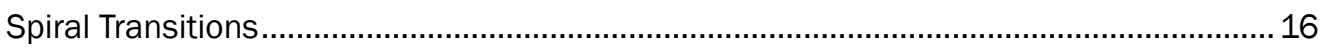

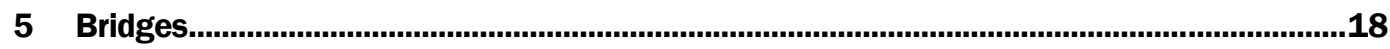

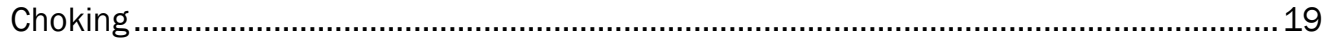

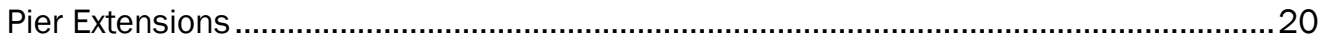

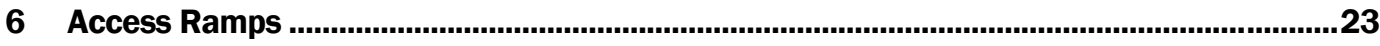

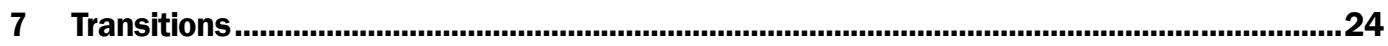

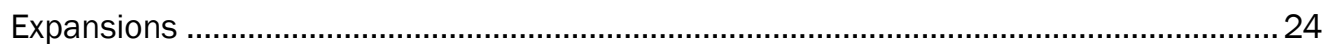

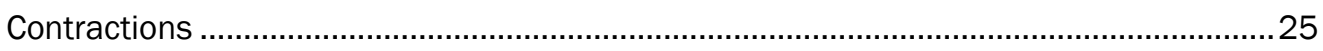

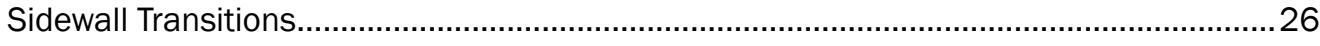

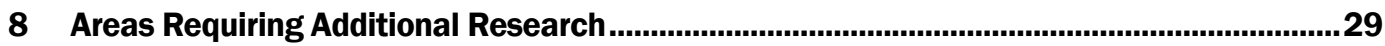

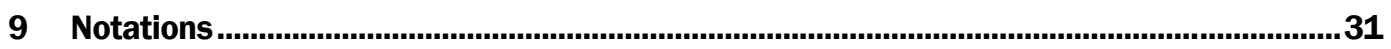

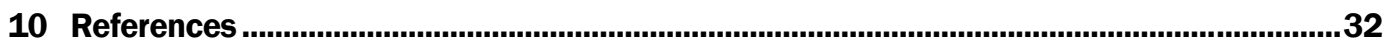

\section{Report Documentation Page}




\section{Figures}

\section{Figures}

Figure 1. Supercritical flow in a channel bend. .............................................................................. 2

Figure 2. Specific energy curve for open channel flow. .................................................................... 5

Figure 3. Trapezoidal confluence from Highway Research Board 1966............................................ 7

Figure 4. Dry bed view of 1:16-scale model of trapezoidal channel junction, looking

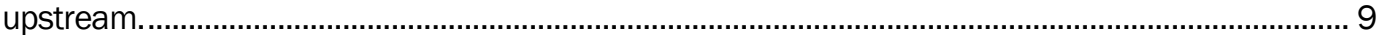

Figure 5. Dry bed view of 1:16-scale model of trapezoidal junction, looking downstream. ............. 10

Figure 6. Design flow conditions in 1:16-scale trapezoidal channel junction, looking

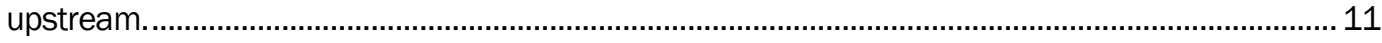

Figure 7. Attachment 1 from Los Angeles District's H \& H Policy Memorandum No. 1..................... 12

Figure 8. Attachment 2 from Los Angeles District's H \& H Policy Memorandum No. 1. ................... 13

Figure 9. Side-channel spillway inlet from Los Angeles County Flood Control District (1982).

Figure 10. Superelevation of water surface in a bend. .............................................................. 16

Figure 11. Plan and elevation of compound curve layout. The banking e, is a function of $V=$ average velocity, $b=$ channel width, $R c=$ radius of curvature at the channel center line, and $g=$ gravitational acceleration...................................................................................... 17

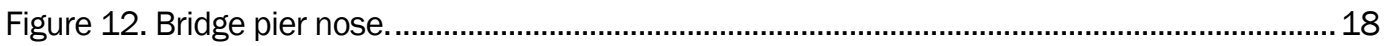

Figure 13. Bridge flow classification...................................................................................... 19

Figure 14. Example of bridge pier with pier extension................................................................ 21

Figure 15. Flow conditions in 1:50-scale model of Rio Hondo River, debris on bridge pier.............. 21

Figure 16. Flow conditions in 1:50-scale model of Rio Hondo River, debris on extended bridge pier.

Figure 17. Half-plan sketch of expansion layout for supercritical flow.............................................2 25

Figure 18. Supercritical flow contraction, rectangular channel.....................................................2

Figure 19. Rectangular-to-trapezoidal transition types.................................................................. 27

Figure 20. Trapezoidal (1V on 2H)-to-rectangular transition, Kahoma Stream Channel, Maui, $\mathrm{HI}$. 


\section{Preface}

The hydraulic design concepts presented in this report were gathered under the sponsorship of the Urban Flood and Channel Restoration Demonstration Program for Arid and Semi-Arid Regions (UFDP). This work was conducted in the Coastal and Hydraulics Laboratory (CHL) of the U.S. Army Engineer Research and Development Center (ERDC) during the period of July 2003 to September 2003 under the direction of Thomas W. Richardson, Director, CHL; Dr. William D. Martin, Deputy Director, CHL; and Donald C. Wilson, former Chief of the Navigation Branch, CHL.

This review of the state of hydraulic design guidance for high-velocity channels was conducted by Dr. Richard L. Stockstill of the Navigation Branch. Acknowledgements are made to Meg Jonas, River Engineering Branch, CHL, and Dr. Jennifer G. Duan, of the Desert Research Institute, Gale W. Fraser, General Manager/Chief Engineer and Stephen C. Roberts, Engineering Manager, Clark County Regional Flood Control District, for their guidance in preparation of this document. Dr. John E. Hite, CHL, provided peer review of the report.

Dr. James R. Houston was Director of ERDC. COL James R. Rowan was Commander and Executive Director. 


\section{Introduction}

This document is a proposed extension of the Hydrologic Criteria and Drainage Design Manual (Clark County Regional Flood Control District 1999) of the Clark County Regional Flood Control District (CCRFCD), Nevada. The Hydrologic Criteria and Drainage Design Manual, has been reviewed and subsequently, areas of need have been identified. The review and expansions are relative to channels conveying supercritical flow and corresponding channel appurtenances.

Hydraulic engineers many times use the term "high-velocity channels" when referring to a lined flood-control channel designed to convey supercritical flow. The designer of these high-velocity channels in urban areas is faced with many questions that are not easily answered. The main concern is the depth of flow in the channel for the design discharge. The depth must be known to determine sidewall heights and minimum bridge soffit elevations. Determining the depth of flow is complicated by side inflows and boundary features such as contractions, expansions, curves, and obstructions to the flow such as bridge piers, and vehicle access ramps. These boundary features in a supercritical channel, cause flow disturbances, which can result in a significant increase in the local flow depth. An accurate prediction of the water-surface shape (i.e., variations in local depth) is essential in the successful design of a high-velocity channel.

Supercritical flow in channels is characterized by standing waves created by even small changes in the sidewall alignment. Oblique standing waves are created at the beginning of channel bends where the depth along the outer wall increases as the wall exerts a force on the fluid (Figure 1). This depth increase is also realized at the beginning of a channel contraction. The flow along the inside wall at the point of curvature, PC, responds as though it were a channel expansion and the depth decreases. However, away from the walls the flow remains unchanged until the forces generated at the boundaries are present in the form of pressure differences. The standing wave pattern downstream of the initial wave intersection point is not a straight line, because the flow at this point is moving along a curved path. Reflections of these waves continue over long distances downstream of the curve. The water-surface setup, or superelevation, in rectangular channel bends is significantly greater in supercritical flow than in 
subcritical flow and the superelevation in trapezoidal channels results in runup on the side slope at the outside of the bend and drawdown on the inside side slope.

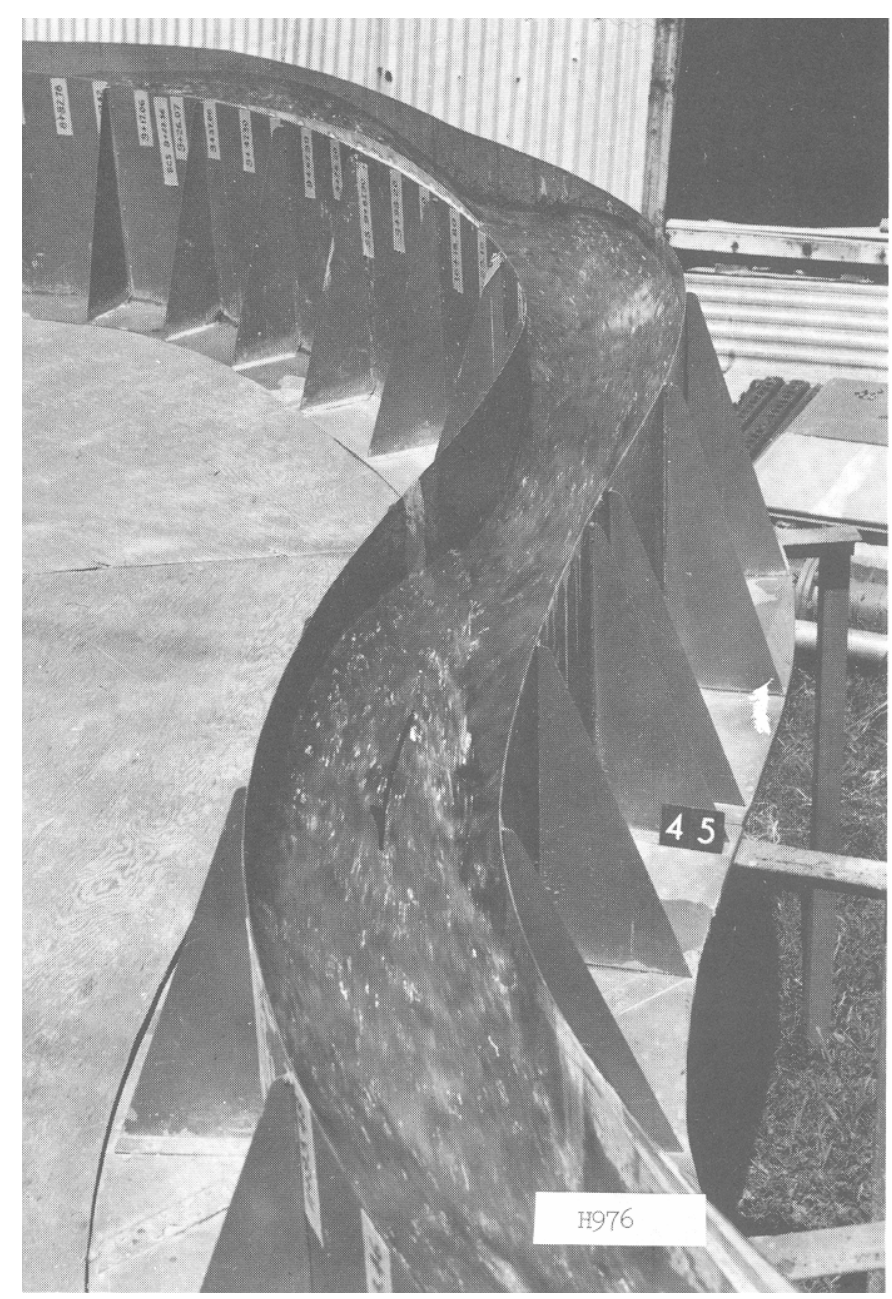

Figure 1. Supercritical flow in a channel bend.

Ippen (1951) details the treatment of oblique standing waves for supercritical flow at small changes in the vertical sidewall boundary alignment. Ippen gives the oblique wave angle and the resulting wave height. Watersurface disturbances are analyzed by either assuming constant specific energy or by considering the energy loss across the disturbance. The first assumption is appropriate for gradual water-surface changes, while analyses of large standing-wave fronts must consider energy losses. In his analysis, Ippen makes the assumptions that the flow is steady, the pressure distribution is hydrostatic, the velocity does not vary in the vertical, and the channel is frictionless or that the friction slope is parallel to the channel slope. 
The cross-sectional shape of high-velocity channels is generally either rectangular or trapezoidal, the choice of which is dictated by optimization of hydraulic and economic concerns. The economic tradeoff of rectangular versus trapezoidal channels is that rectangular channels require less real estate; however, construction of rectangular channels is more costly than trapezoidal channels. The structural cost of vertical sidewalls may be greater than the cost of acquiring the additional real estate required conveying the flood flow in a trapezoidal channel. Channel cross-section shapes are selected based on adequate hydraulic capacity in conjunction with the minimum cost of construction and maintenance. The total cost includes costs of right of way, the cost of construction and modification of structures such as bridges, and maintenance costs associated with the removal of sediment and/or debris.

The flow in trapezoidal high-velocity channels differs markedly from flow in rectangular channels. Straight reaches of rectangular channels produce a fairly uniform distribution of velocity at a cross section, although the actual distribution is influenced by the channel boundary and free-surface drag and therefore depends on the channel's width-to-depth aspect ratio (Rouse 1961). However, the velocity variations across a section of straight trapezoidal channel are large. Flow along the side slopes near the water's edge is severely retarded by bed drag as the flow depth decreases. The local Froude number near the side boundary approaches zero. The local flow regime at a cross section of a trapezoidal high-velocity channel can be supercritical at the center and subcritical near the water's edge. The flow over a portion of the side slope may be at or near critical. This mixture of subcritical and supercritical flow regimes can lead to flow instabilities and associated fluctuations in depth and velocity. 


\section{General Design Considerations}

Typically, in engineering applications, open channel flow is analyzed using empirical one-dimensional hydraulic equations where the velocity and the water-surface elevation are assumed constant over a cross section. Fluid frictional losses in uniform flow in straight prismatic channel sections are represented with either the Manning or Chezy equation. Empirical expressions have been developed to estimate the head losses (Henderson 1966) and superelevation of the water surface in channel curves (Woodward and Posey 1941). Flow obstructions such as bridge piers have been studied and parameters such as pier loss coefficients (U.S. Army Engineer District, Los Angeles, 1939) have been quantified for simple geometric configurations. Hydraulic research has resulted in design criteria for channel width transitions (Brater and King 1976; U.S. Bureau of Reclamation 1967; Ippen and Dawson 1951). The general location of a hydraulic jump in a straight prismatic rectangular channel is determined by backwater computations from a downstream control point and forward step computations from an upstream control point until the momentum equation of the hydraulic jump is satisfied.

Flow stability is an issue that must be considered in the design of highvelocity channels. The depth associated with conditions when the flow is near critical is inherently unstable because small changes in specific energy can lead to large changes in the local depth of flow. This fact is best understood in terms of the specific energy diagram shown in Figure 2 where the specific energy, $E$ is:

$$
\mathrm{E}=\mathrm{h}+\frac{\mathrm{V}^{2}}{2 \mathrm{~g}}=\mathrm{h}+\frac{\mathrm{q}^{2}}{2 \mathrm{gh}^{2}}
$$

where

$$
\begin{aligned}
\mathrm{h} & =\text { flow depth } \\
\mathrm{V} & =\text { velocity } \\
\mathrm{q} & =\text { unit discharge }=\mathrm{Vh} \\
\mathrm{g} & =\text { acceleration due to gravity }
\end{aligned}
$$




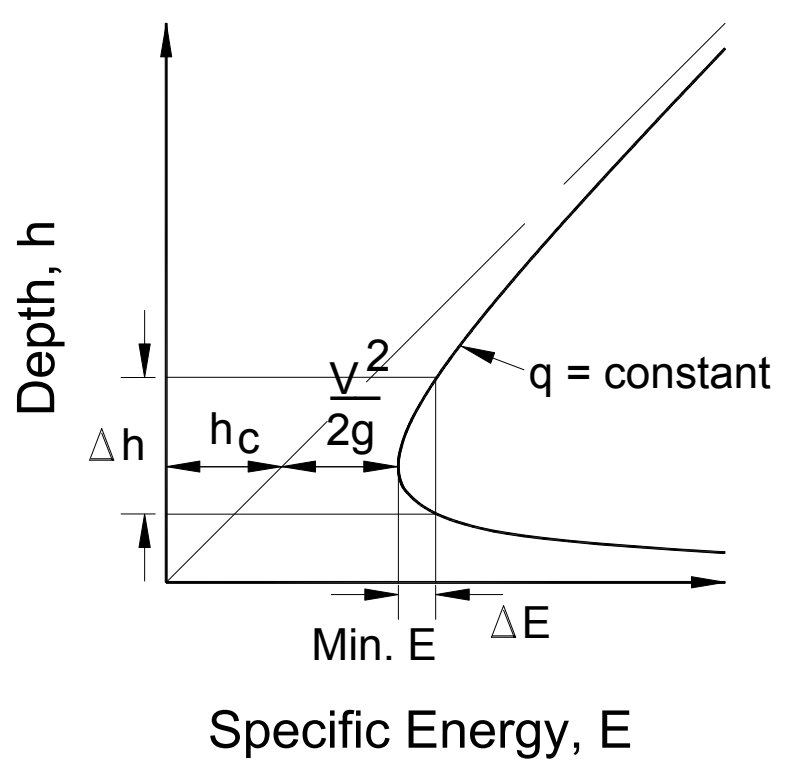

Figure 2. Specific energy curve for open channel flow.

The specific energy curve shown in Figure 2 illustrates that when the flow is near critical, the conditions associated with a minimum specific energy, a small loss in energy can cause large changes in flow depth. The Froude number, $F_{r}$ as defined $F_{r}=\frac{V}{\sqrt{g h}}$ is unity at critical flow conditions. The Froude number is greater than unity (supercritical flow) for values of depth less than critical depth (depth at which specific energy is a minimum) and less than unity (subcritical flow) for values of depth greater than critical. Also, instabilities can develop when the flow is above a Froude number of 2. Here, roll waves can occur as a result of surface perturbations introduced by boundary changes (Henderson 1966). So, the hydraulic design of man-made channels should try to produce channels that convey flood flows between Froude numbers of 1.13 (corresponding to a depth less than $0.9 h_{c}$, where $h_{c}$ is the critical depth, see Figure 2) and yet less than 2.0. Channels conveying subcritical flow should not exceed a Froude number of 0.86 (corresponding to a depth greater than $1.1 h_{c}$ ) (Headquarters, U.S. Army Corps of Engineers 1991). 


\section{Junctions}

Confluences of supercritical flow are complicated by the fact that standing waves are generated at any and all boundary alignment changes. One such boundary feature is the end of the common wall that separates the two channels. Thicker walls trigger larger flow disturbances, which are manifested as standing waves. This is particularly true if the water-surface elevations of the two channels are significantly different. Peak flows in the side channel and the main channel may not occur at the same time during a storm event. Therefore, analysis and design should be conducted at all probable combinations, as well as at the design flow conditions. The design flows may not produce the largest water-surface elevations because large standing waves that result from unequal water-surface elevations can result in locally high water-surface elevations. Introduction of the sidechannel flow with the main-channel flow should be done in such a manner that the water-surface elevations in each channel are nearly equal. Ideally, the angle of the junction will be zero and never greater than $12 \mathrm{deg}$ (HQUSACE 1991).

\section{Rectangular Confluences}

The combining of two channels, each being of rectangular cross-sectional shape, is thoroughly treated in EM 1110-2-1601 (HQUSACE 1991). Deviances from the recommendations provided in EM 1110-2-1601 can, in some cases, be evaluated using the work of Rice (1985). Rice (1985) provides design guidance for rectangular junctions with supercritical flow. Flow depths with junction angles of 30, 60, and 90 deg were measured for various lateral-to-main channel discharge ratios. This guidance aims to ensure that if a hydraulic jump is formed when the lateral flows intersect the main-channel flow, that the jump is contained within the junction area. However, these junction configurations are relatively expensive because of the wall heights required to contain a hydraulic jump.

A hydraulic jump can be described graphically on the specific energy diagram on Figure 2. The jump is characterized by a rapid change increase in depth and decrease in velocity. Strong jumps are stationary breaking waves that produce large energy losses. Graphically on specific energy 
diagram, a hydraulic jump would "jump" from the lower portion of the cruve (supercritical flow) to the upper portion of the same curve (subcritical flow), but also to the left due to the loss of energy.

\section{Trapezoidal Confluences}

Trapezoidal confluences present unique problems when both channels are conveying supercritical flow. The common wall separating the channels becomes an obstacle to bringing the two flows together. Limited work has been focused on the design of trapezoidal channels merging while conveying supercritical flow. The Highway Research Board sponsored a study in which various trapezoidal junction configurations were tested. The best design tested, which allowed for varying flow combinations between the main and tributary channels included a vertical wall as the two common side slopes merged. This vertical common wall was tapered to zero height. The design guidance from this study (Highway Research Board 1966) recommended that the length of the height transition be a function of Froude number. Figure 3 is a sketch taken from National Research Council (U.S.) (Highway Research Board 1966).

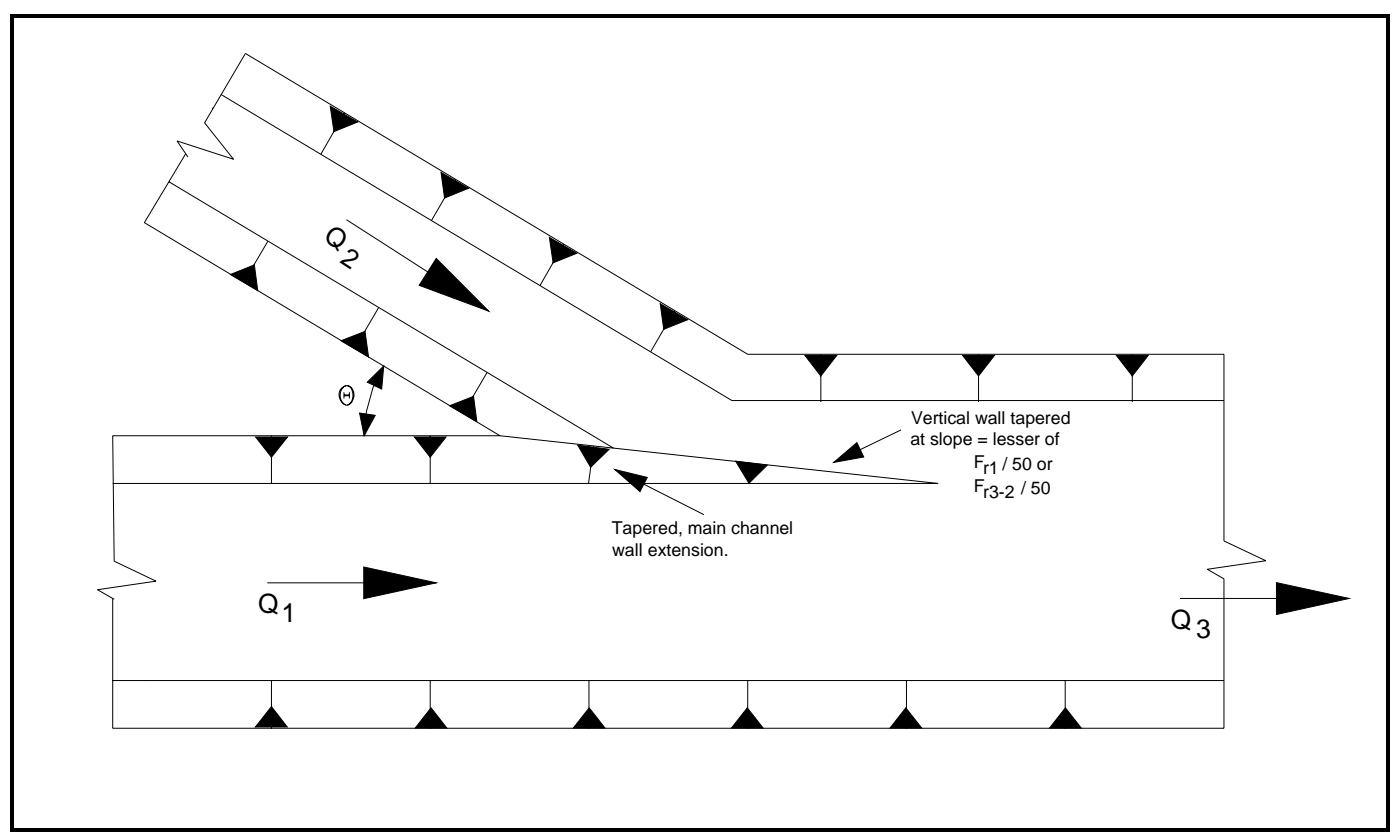

Figure 3. Trapezoidal confluence from Highway Research Board 1966.

A study was initiated by the Los Angeles District at the U.S. Army Engineer Waterways Experiment Station, in late 1992. The purpose of this study was to evaluate proposed trapezoidal junctions as part of the Las Vegas Wash and Tributaries Model Study. One confluence was constructed 
at a scale of 1:16. The side slopes of both the main channel and the tributary were laid on $1 \mathrm{~V}$ on $2 \mathrm{H}$. The common divider wall was designed as laid out in Highway Research Board (1966) report and is shown in Figures 4 and 5. After construction of the first model, the study was terminated because the Los Angeles District decided to make each of the project's confluences rectangular rather than trapezoidal. It was determined that rectangular junction design guidance was sufficient, and therefore, the model study was ended. However, after construction of the first junction, the model was operated to qualitatively evaluate the performance of the proposed junction. The photo provided in Figure 6 shows the flow conditions generated by tributary flow only in this trapezoidal junction. The proposed junction did not perform as well as was expected. Further study found that the design flows produced a choked condition at the confluence and caused significant increase in the depth upstream and within the junction.

Perhaps, due to the large amount of real estate required for trapezoidal junctions, the most economical alternative for the merging of two trapezoidal channels is that the two trapezoidal channels be transitioned into rectangular channels, merged as the EM 1110-2-1601 guidance provides, and then the combined channel can be transitioned back to a channel with sloping side walls. 


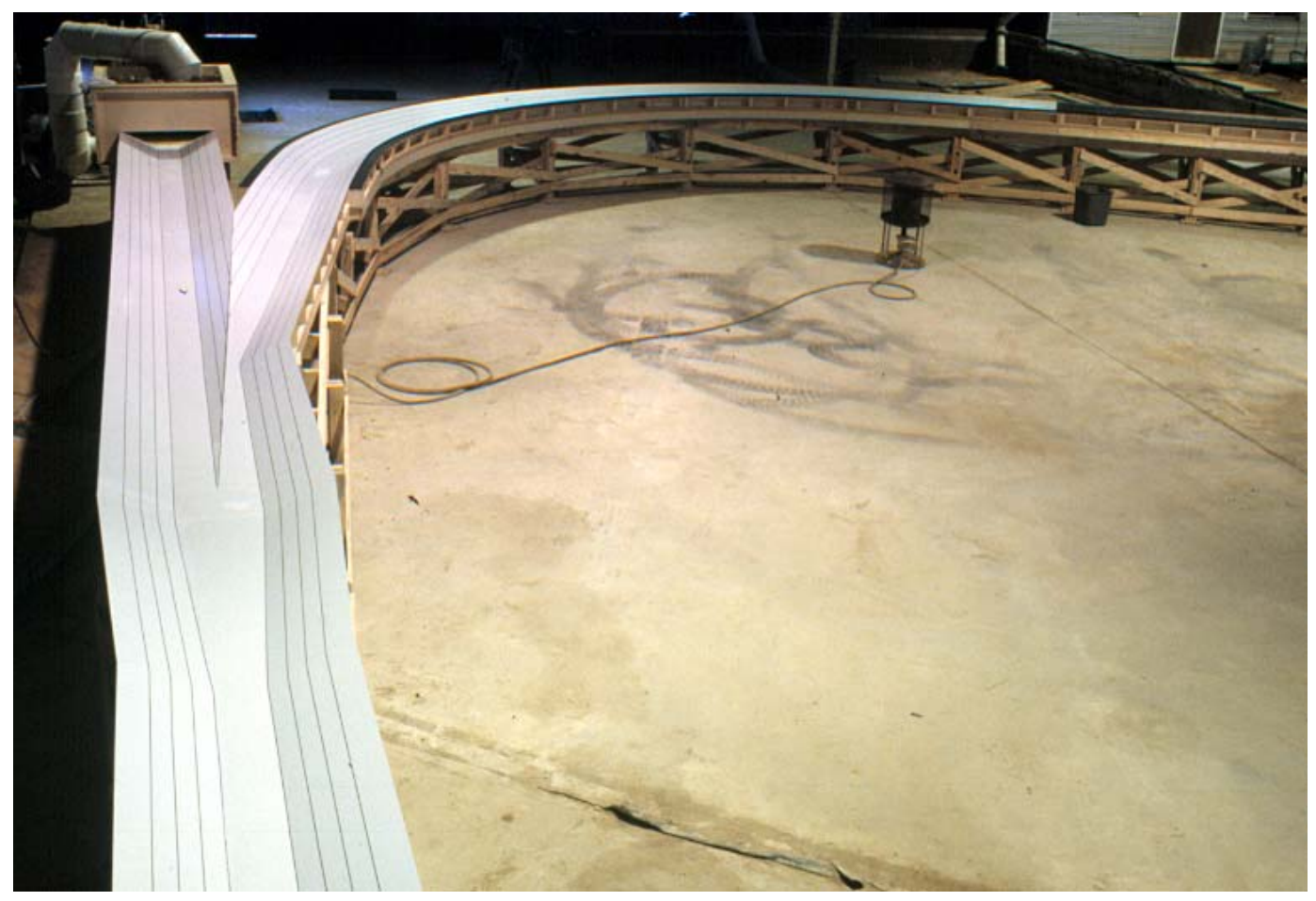

Figure 4. Dry bed view of 1:16-scale model of trapezoidal channel junction, looking upstream. 


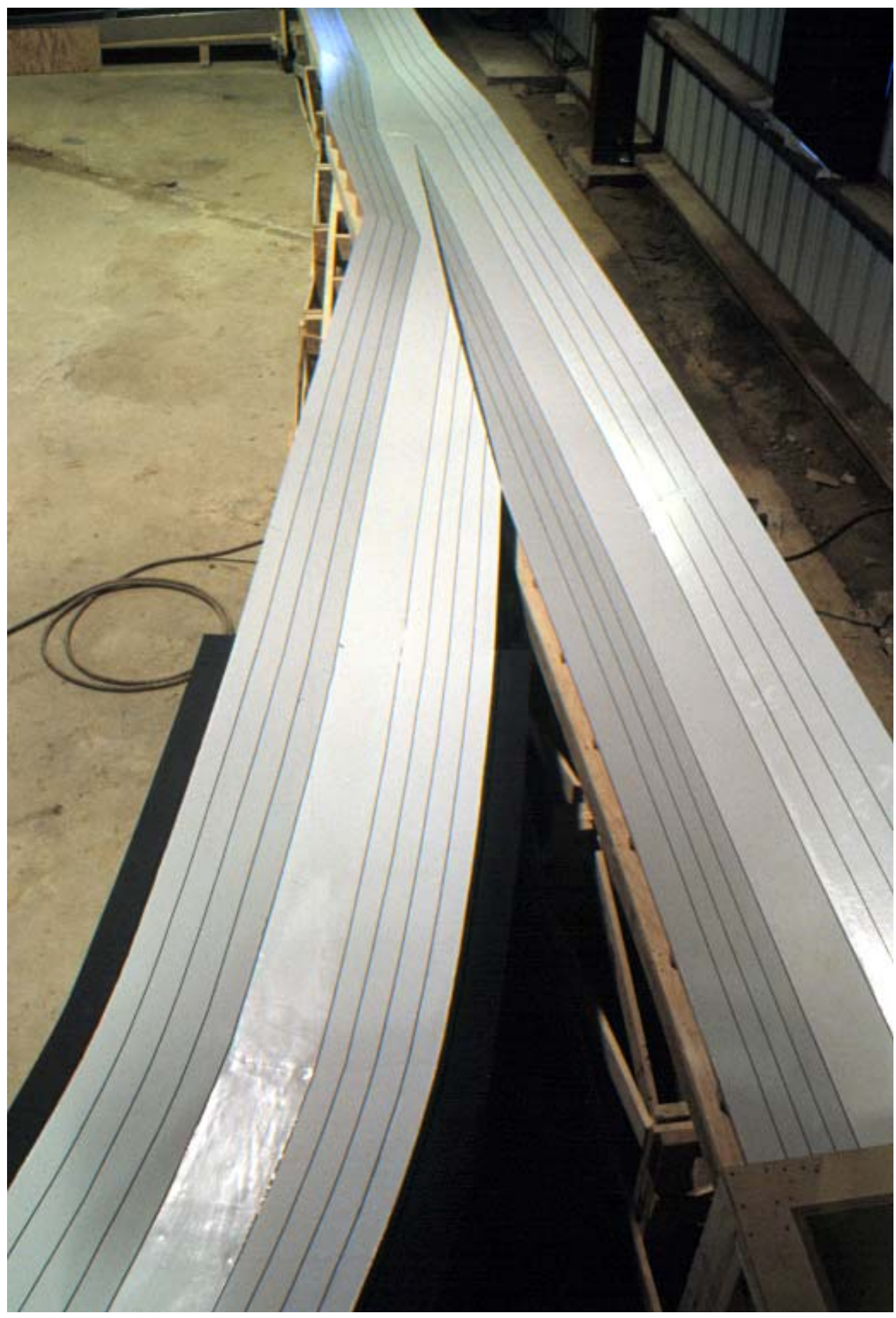

Figure 5. Dry bed view of 1:16-scale model of trapezoidal junction, looking downstream. 


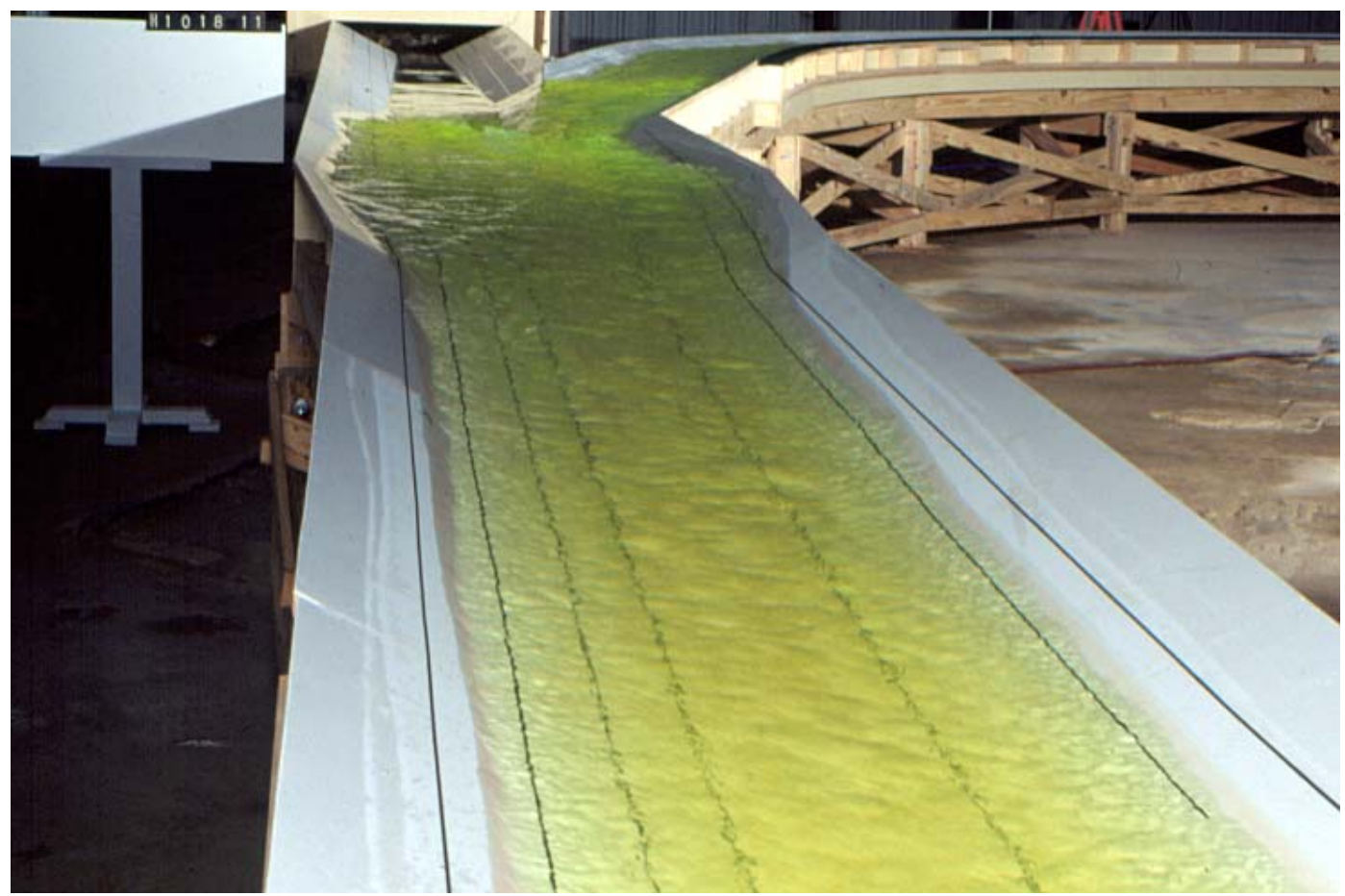

Figure 6. Design flow conditions in 1:16-scale trapezoidal channel junction, looking upstream.

\section{Laterals}

The introduction of storm drain flow is complicated by the fact that generally, these confluences occur near road crossings where utilities and right of way constraints limit geometric flexibility in design. The Los Angeles District requires $1.2 \mathrm{~m}$ ( $4 \mathrm{ft}$ ) of main channel flow submergence above the pipe's soffit. Figures 7 and 8 are taken from the Los Angeles District's H \& H Policy Memorandum No. 1. Lateral pipes are allowed if the culvert flow is less than 10 percent of the main-channel flow. If the culvert flow is larger than 10 percent of the main channel flow rate, then a confluence is constructed according to EM 1110-2-1601.

\section{Side Channel Spillway Inlet}

The Los Angeles County Flood Control District (1982) provides design procedure for these structures. The manual states that this procedure is taken from the Los Angeles District. The side inflow is introduced to the main channel using the common wall as a spillway crest. As discharge is merged from the side channel, the side channel width is reduced. An example is shown in Figure 9. 


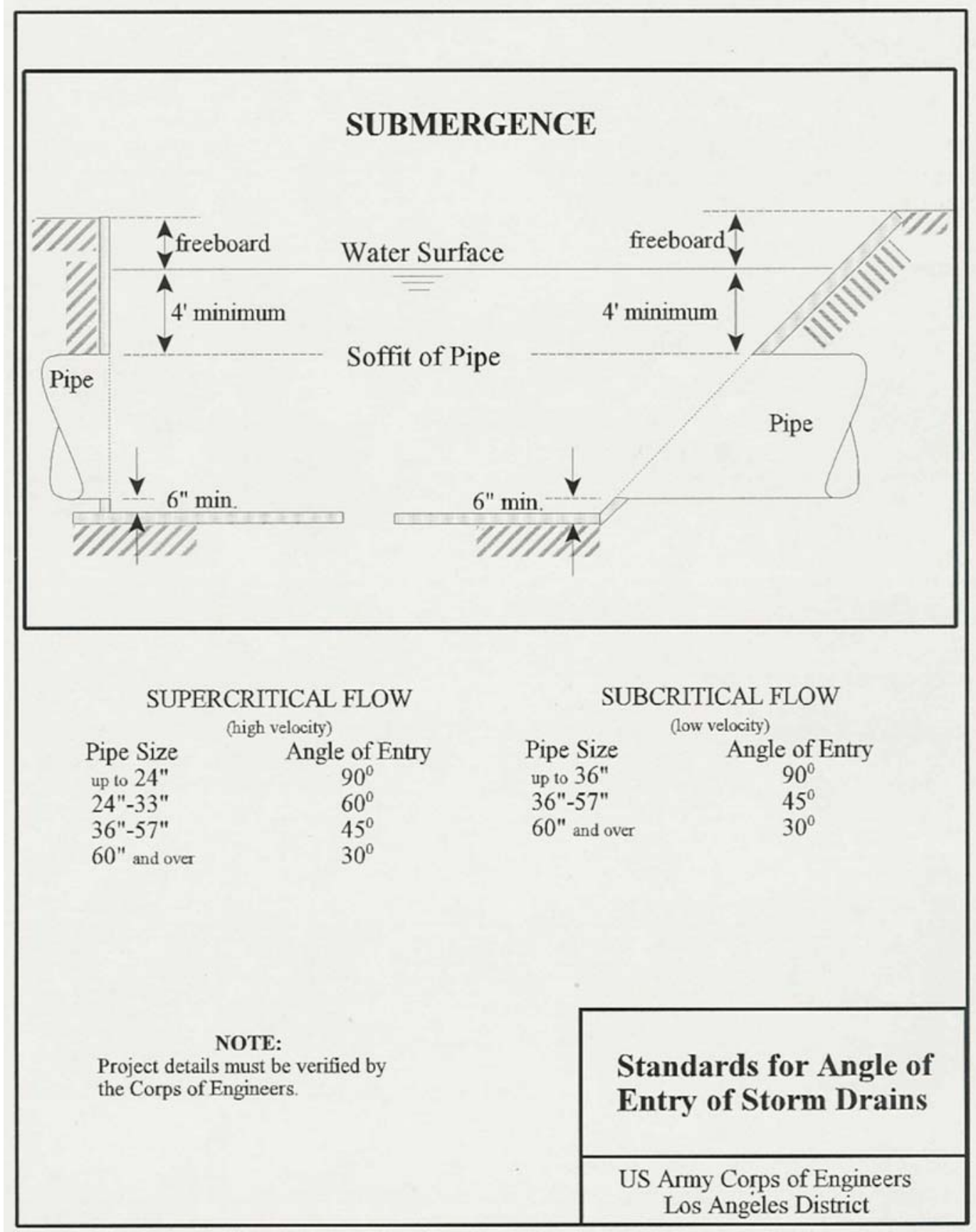

Figure 7. Attachment 1 from Los Angeles District's H \& H Policy Memorandum No. 1. 


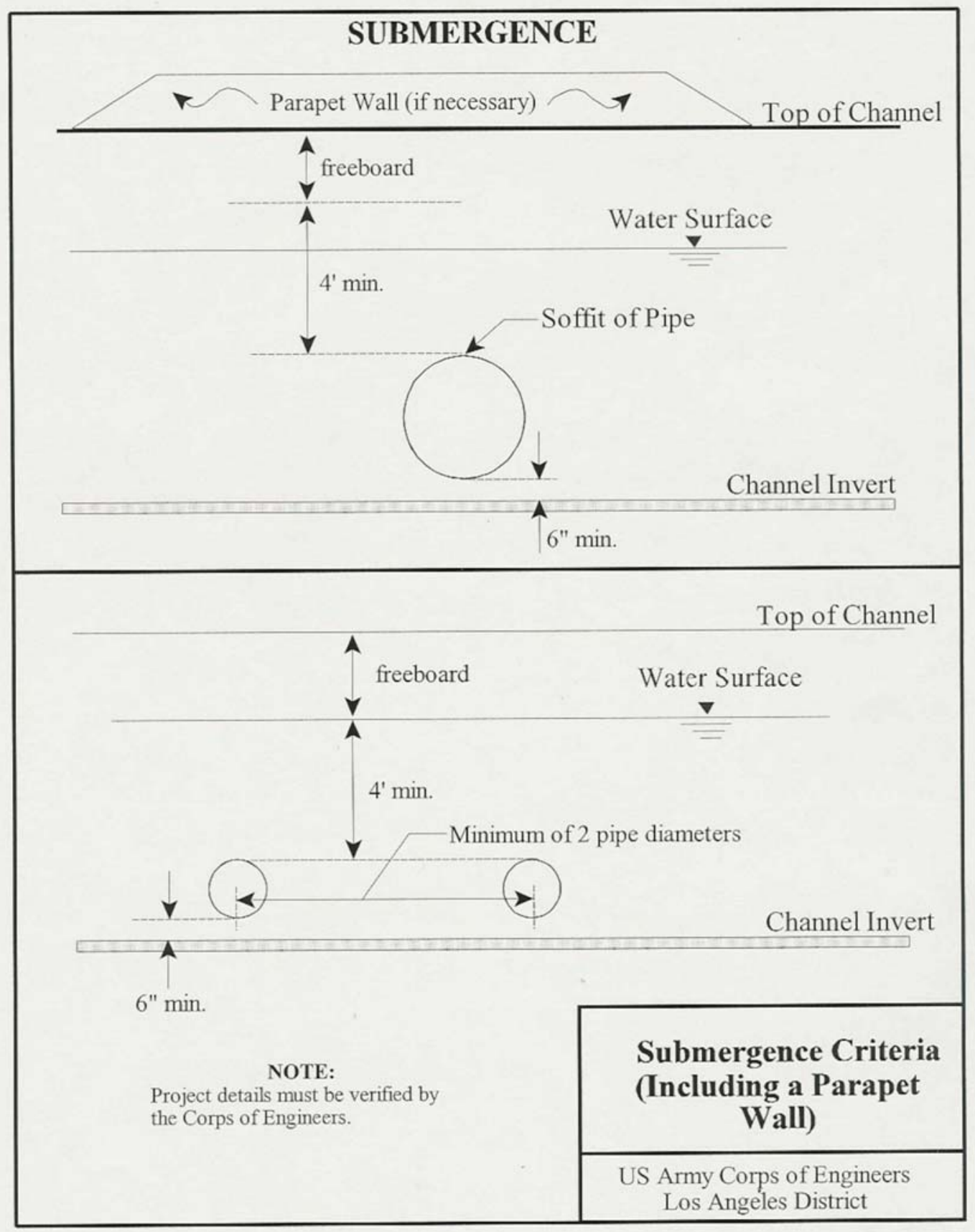

Figure 8. Attachment 2 from Los Angeles District's H \& H Policy Memorandum No. 1. 


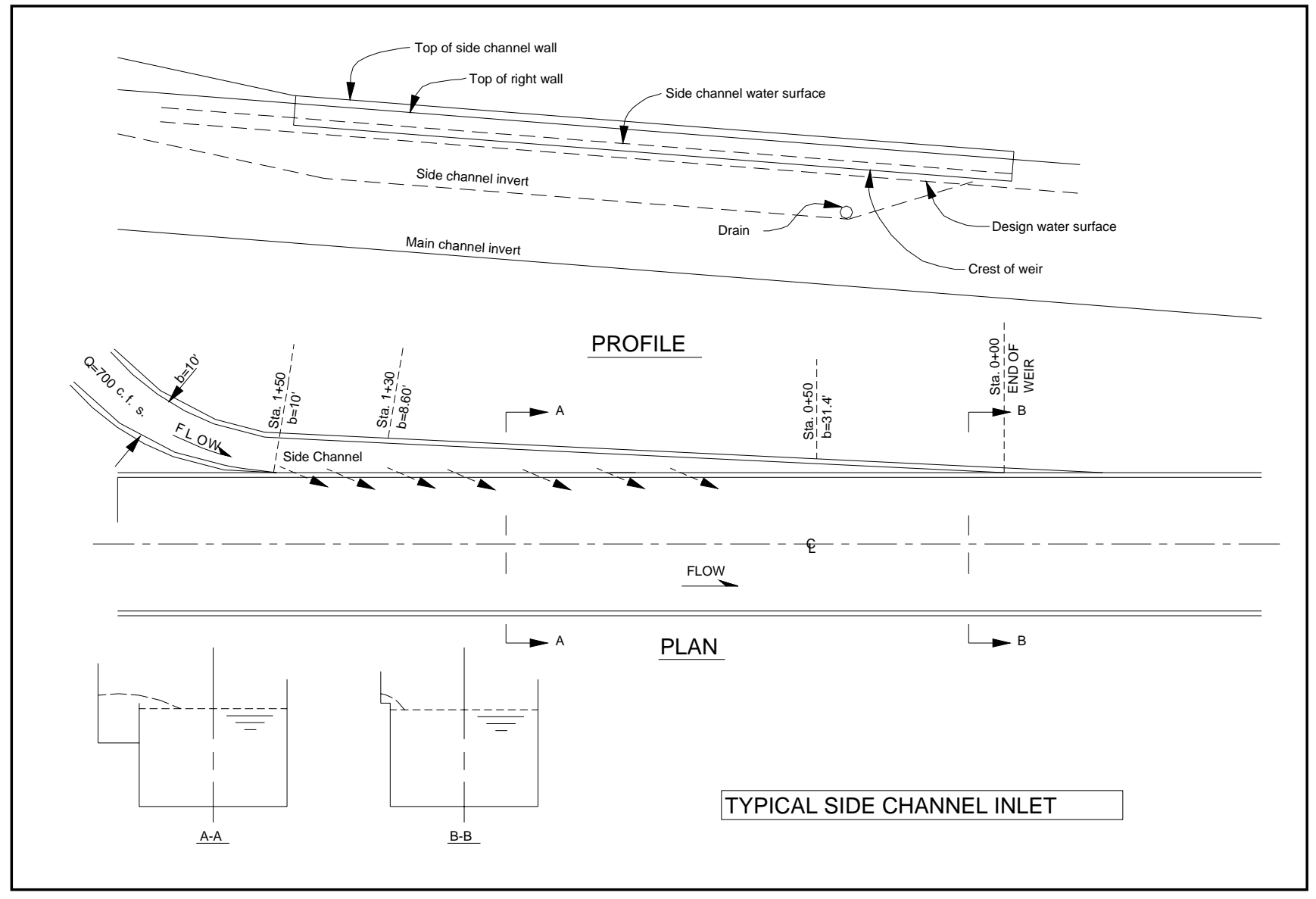

Figure 9. Side-channel spillway inlet from Los Angeles County Flood Control District (1982). 


\section{Bends}

Knapp (1951) gives a general description of supercritical flow in rectangular and trapezoidal channels. He provides a means of estimating the superelevation and standing waves within a curve and points out that waves generated in a curve are continued downstream. Knapp's assumptions include those given by Ippen (1951) with the addition that the velocity is constant across the cross section. Knapp states that in trapezoidal channels the depth is not constant and that the wave celerity, therefore, varies throughout the cross section making his findings much less applicable to trapezoidal channels. He cautions channel designers that the additive effects of curves separated by short distances are not treated in his analyses since his method neglects the nonuniform velocity distribution across the beginning section of the downstream curve. The skewed velocity distribution entering the downstream curve is generated by flow through the upstream curve.

\section{Superelevation of Water Surface and Banking}

For supercritical flow, EM 1110-2-1601 provides the superelevation of the water surface as flow traverses around a curve:

$$
\Delta \mathrm{h}=\mathrm{CW} \frac{\mathrm{V}^{2}}{\mathrm{gr}}
$$

where

$$
\begin{aligned}
& \mathrm{W}=\text { channel width at elevation of center line water surface } \\
& \mathrm{V}=\text { average velocity } \\
& \mathrm{g}=\text { acceleration due to gravity } \\
& \mathrm{r}=\text { center line radius of curvature }
\end{aligned}
$$

Figure 10 shows the geometric variables as applicable to a trapezoidal channel. The "radius" is the center line radius of curvature. $\mathrm{C}=1.0$ for rectangular and trapezoidal channels in simple curves, $\mathrm{C}=0.5$ in rectangular channels with spirals (with and without banking) and $\mathrm{C}=1.0$ in trapezoidal channels with spiral transitions. 


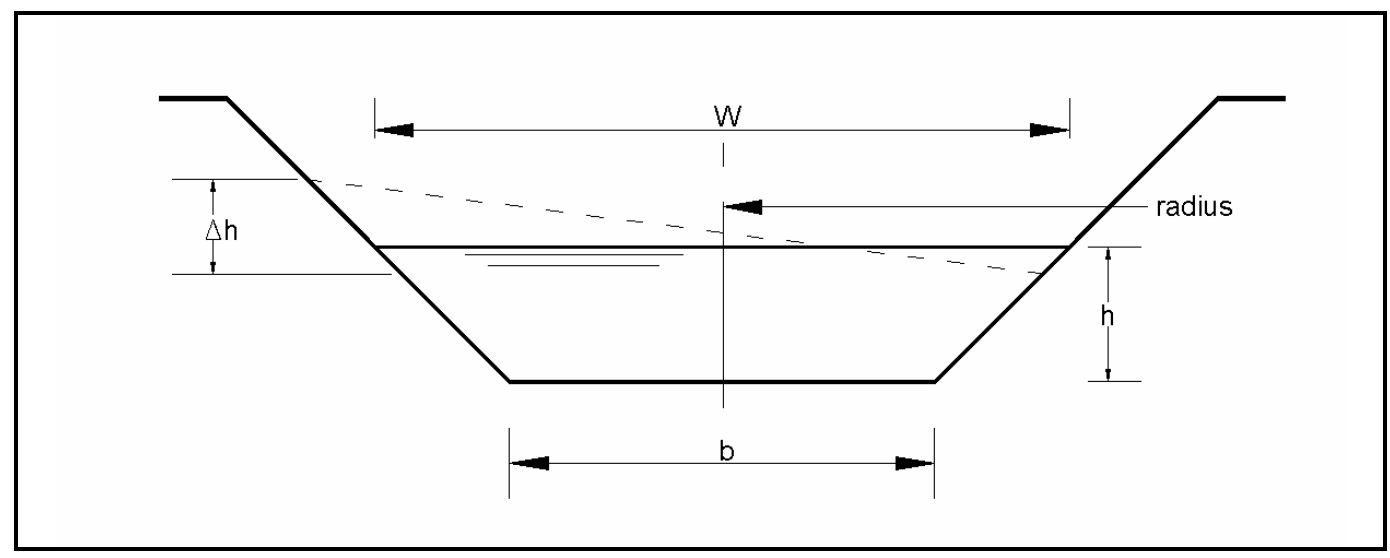

Figure 10. Superelevation of water surface in a bend.

\section{Spiral Transitions}

The minimum length of spiral transitions for banked curves is given in EM 1110-2-1601 as $\mathrm{L}_{\mathrm{s}}=30 \Delta \mathrm{h}$. This guidance was developed by the Los Angeles District Laboratory (U.S. Army Engineer District, Los Angeles, 1972). In discussions provided by Douma to the Ippen and Dawson (1951) paper (see discussion section in Ippen and Dawson 1951), Douma argues that a longer spiral may be required for unbanked curves, based on the length computed by:

$$
\mathrm{L}_{\mathrm{s}}=1.82 \mathrm{~W} \mathrm{~F}_{\mathrm{r}}
$$

where

$$
\begin{aligned}
& \mathrm{F}_{\mathrm{r}}=\text { approach Froude number } \\
& \qquad \mathrm{F}_{\mathrm{r}}=\frac{\mathrm{V}}{\sqrt{\mathrm{gh}}}
\end{aligned}
$$

with

$$
\begin{aligned}
& \mathrm{V}=\text { velocity } \\
& \mathrm{h}=\text { flow depth at the tangent-to-curve station }
\end{aligned}
$$

The layout of spiral curves is provided in highway alignment handbooks such as Hickerson (1964). The alignment coordinates can be computed using a hand calculator or spreadsheet computer program. A sketch of the layout of a typical compound curve used in high-velocity channels is illustrated in Figure 11. 


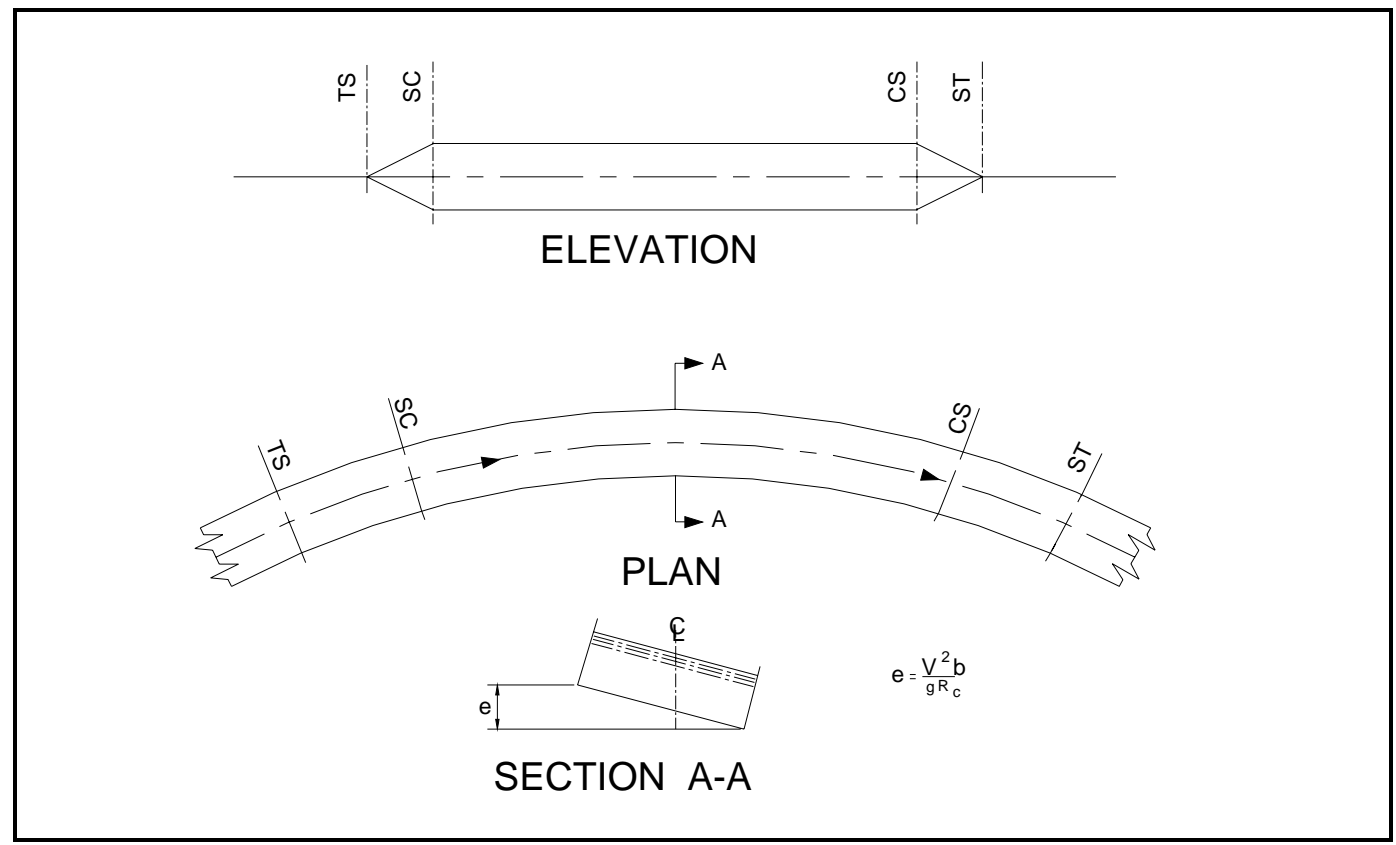

Figure 11. Plan and elevation of compound curve layout. The banking $e$, is a function of $V=$ average velocity, $b=$ channel width, $R c=$ radius of curvature at the channel center line, and $g=$ gravitational acceleration.

To reduce waves generated in curves and to avoid separation of flow from the inner sidewall, a minimum radius is given in EM 1110-2-1601 as:

$$
\mathrm{r}_{\min }=4 \mathrm{WF}_{\mathrm{r}}^{2}
$$

Where right of way problems dictate that a bend of greater curvature than that allowed by the minimum radius given in Equation 5, the effective top flow-width could be reduced with the addition of dividers. These dividers are vertical walls placed within the channel, which in effect divide the flow into multiple channels. Design of a flow splitter's nose should follow that given for the noses of bridge piers (HQUSACE 1991). 


\section{Bridges}

Debris noses are usually placed on the upstream faces of piers subjected to accumulation of debris. The tapered design of debris nose, which is shown on Figure 12, is shaped to shed grasses and woody debris. This passing of debris minimizes accumulation of debris that increases energy losses through the bridge opening and prevents the openings from being clogged. A recent study conducted by Haehnel and Daly (2002) provides methods to evaluate the forces generated as large woody debris strike bridge piers. They show that the existing guidance relating to design for impact loads: impulse-momentum (FEMA 1995), the work-energy (NAASRA 1990), and contact stiffness (AASHTO 1998), are actually equivalent although each requires the specification of an additional parameter.

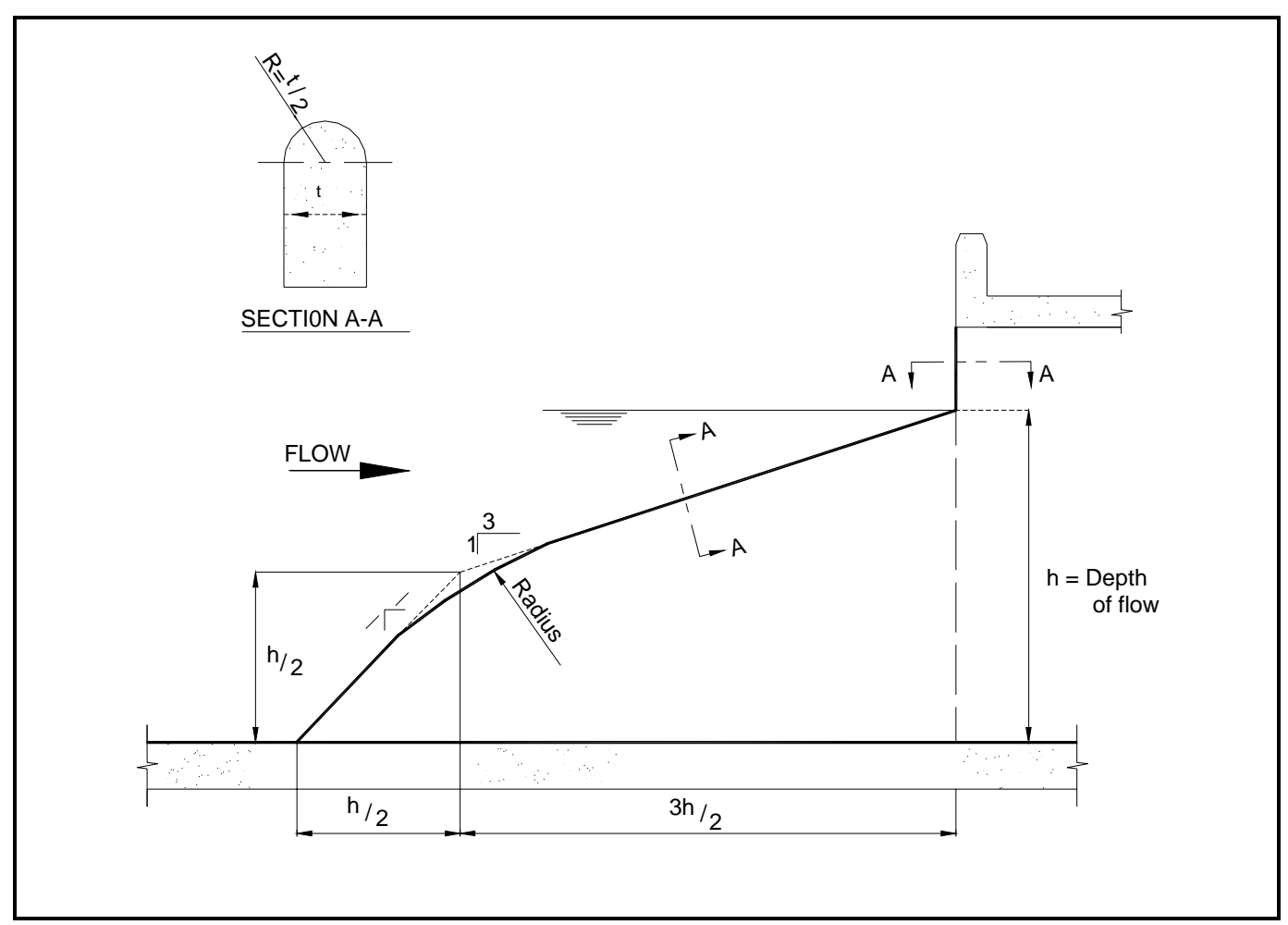

Figure 12. Bridge pier nose.

The submergence of bridges is to be avoided due to the tremendous uplift forces that can be generated. Also, safety is a serious concern for bridges with water on their deck as the crossing flow can easily float a vehicle off the roadway and into the high-velocity flow, which can lead to loss of life. 


\section{Choking}

Bridge piers located in flood-control channels are classified by the relation of flow depth through the bridge section to critical depth upstream, between, and downstream of the piers (see Figure 13). The term Class B flow is applied to conditions in which subcritical flow approaches the bridge, passes through critical depth at a point along the piers, and then jumps to subcritical flow or remains supercritical depending on the downstream conditions. The far field flow upstream of the bridge may be subcritical or supercritical. Class B type flow occurs in hydraulically steep channels in which the bridge pier constriction chokes the flow producing a hydraulic jump upstream of the piers. The flow downstream of the piers is supercritical and rapidly varied flow occurs through the bridge crossing reach.

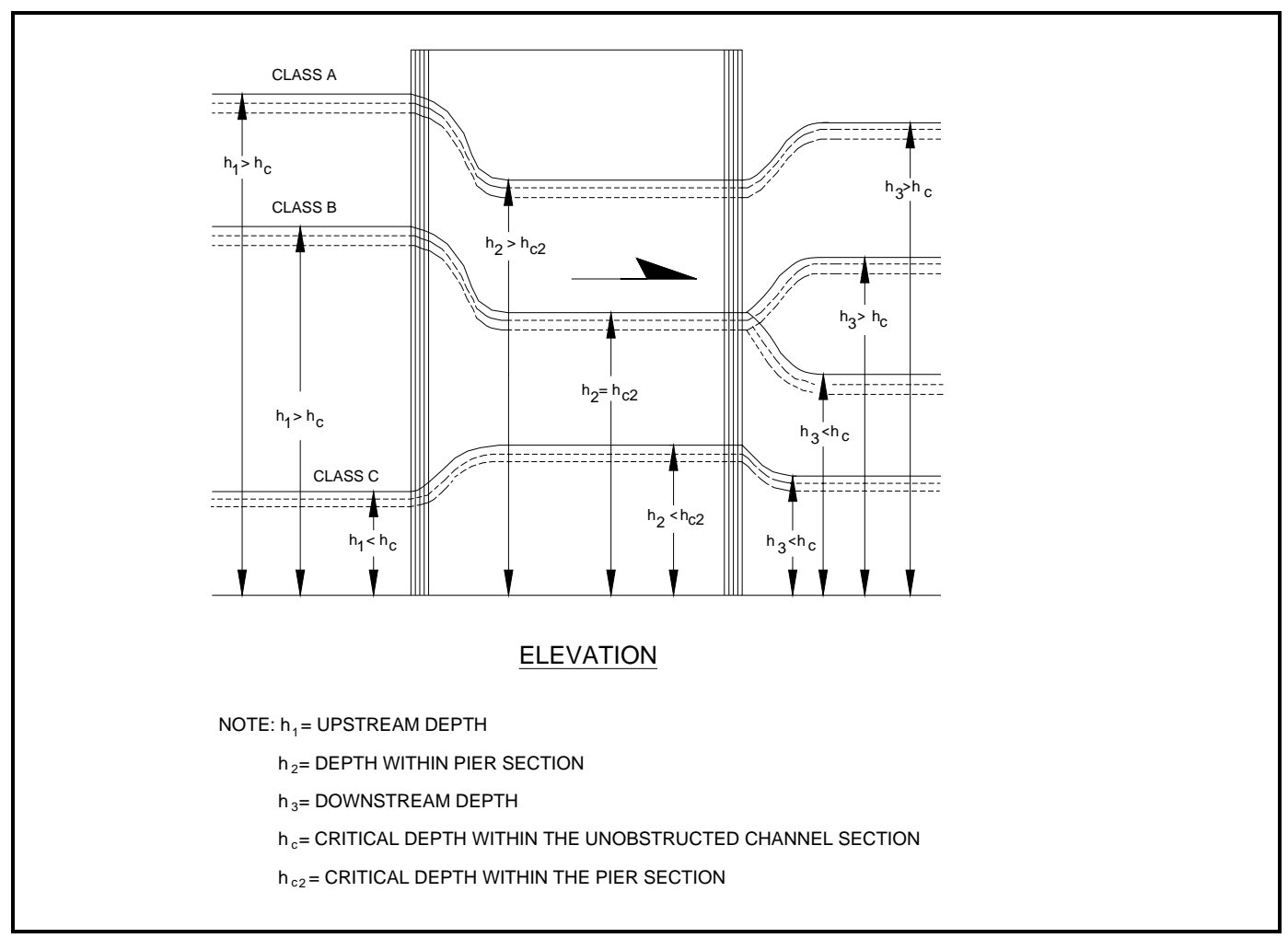

Figure 13. Bridge flow classification.

Analysis of flow conditions in the vicinity of bridge crossings is complicated by the fact that the bridge piers serve as flow obstructions. Bridge pier scour during flood events is a major engineering concern; however, in concrete-lined high-velocity channels, scour is not a problem, but pier effects on the flow are significant. Flood-control channel design is primarily interested in sizing channel sidewall heights. An accurate prediction of the flow depth is imperative in successful design of flood-control channels. 
Flow depth prediction is complicated by bridge piers, which can influence the flow depth both upstream and downstream of the bridge crossing.

Bridge piers, located in high-velocity channels where the channel slope produces a normal depth less than critical depth, can choke the flow resulting in backwater effects from the bridge. Choking situations in steep channels produce a hydraulic jump upstream of the bridge. Choking in high-velocity channels results in flow depths that are significantly higher than those in the absence of choke. Downstream of the bridge, supercritical flow through the bridge piers produces standing waves generated at the pier tails.

In the analysis of high-velocity channel flow at bridge piers, the design engineer must be able to predict whether the flow obstructions will choke the flow and if they do, determine the upstream depth of flow. The flow depth downstream of the bridge must also be determined and in supercritical flow, the height of standing waves must be predicted. Accurate determination of flow depths are required for sidewall height and minimum bridge soffit elevation determinations.

\section{Pier Extensions}

Stonestreet et al. (1994) provide an overview of the extensive physical model studies of the Los Angeles and Rio Hondo rivers. This particular paper focuses on innovative designs that significantly increased the capacity of existing bridges subject to discharges greater than the design discharge. The idea is to extend bridge piers upstream, thereby causing the flow to pass through critical as it accelerates within the pier constriction. Figure 14 illustrates the general profile of the water-surface response to extension of the bridge piers. Stonestreet (1990) details development of this design strategy in a general study of flow through bridge openings in fixed-bed channels. Illustrations of the effectiveness of these pier extensions are provided in the photos in Figures 15 and 16. These figures from Hite et al. (1993) are photographs of the 1:50-scale model of the Rio Hondo River. Clearly, the pier extensions eliminated the runup and splash on the bridge deck. 


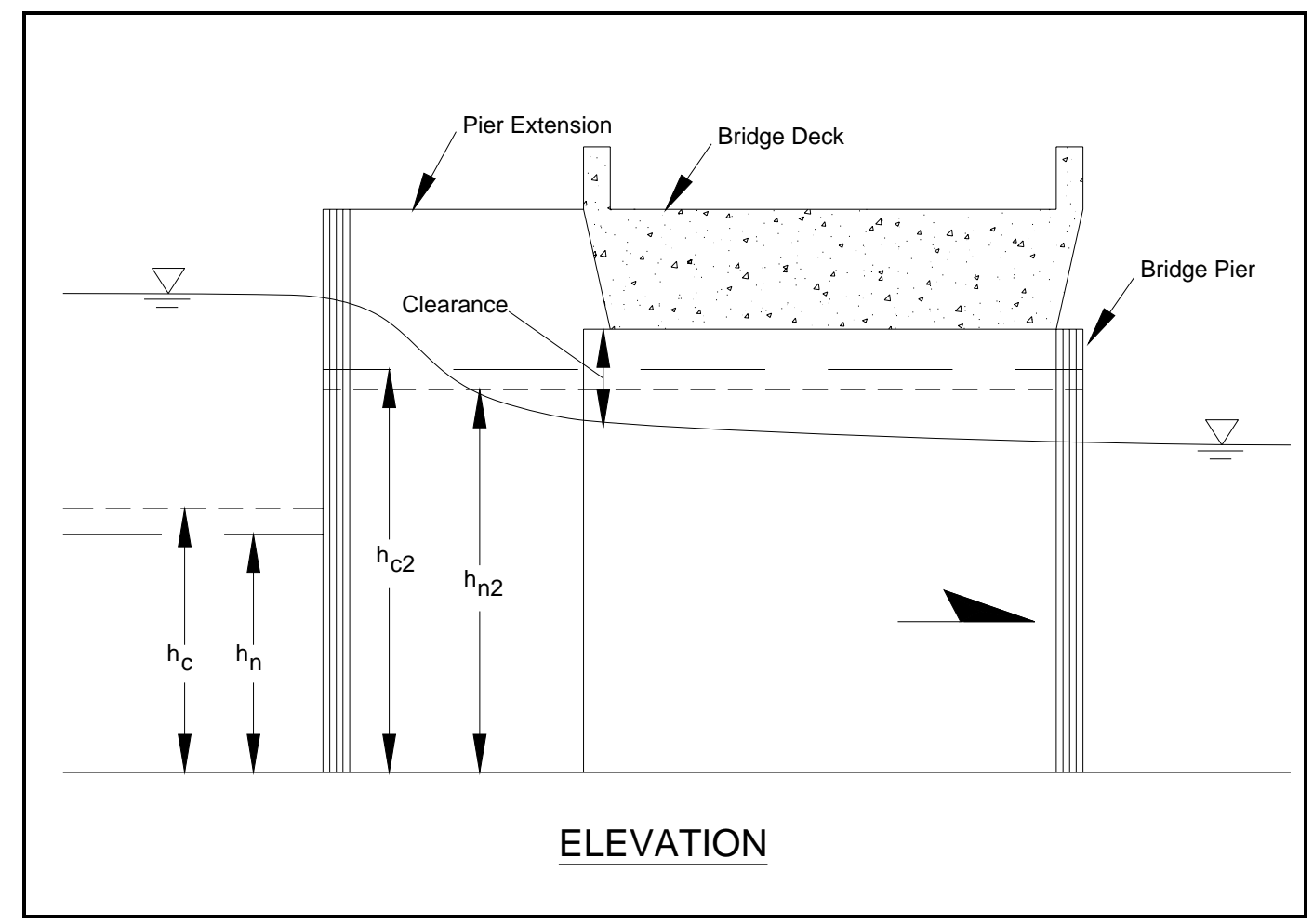

Figure 14. Example of bridge pier with pier extension.

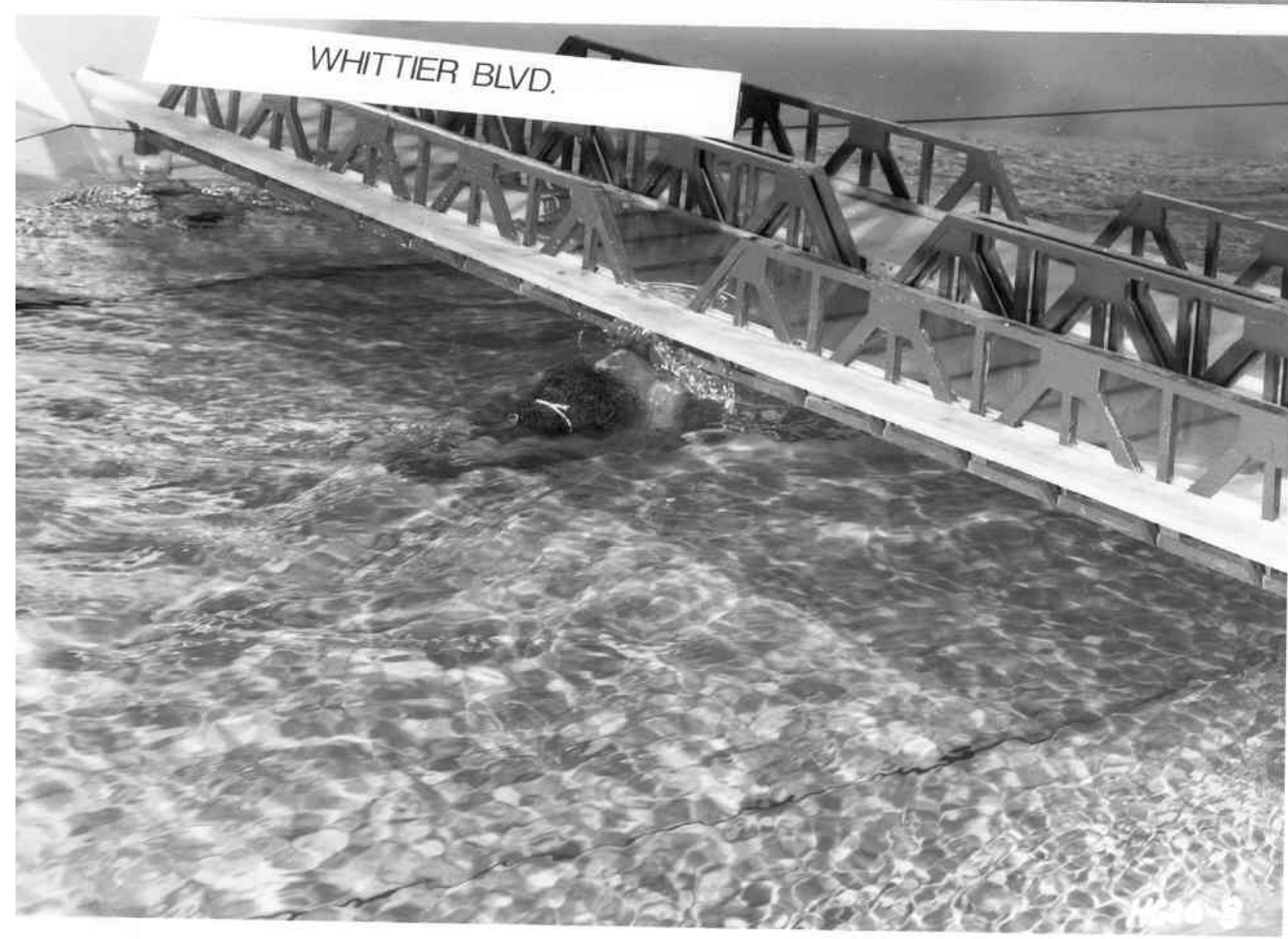

Figure 15. Flow conditions in 1:50-scale model of Rio Hondo River, debris on bridge pier. 


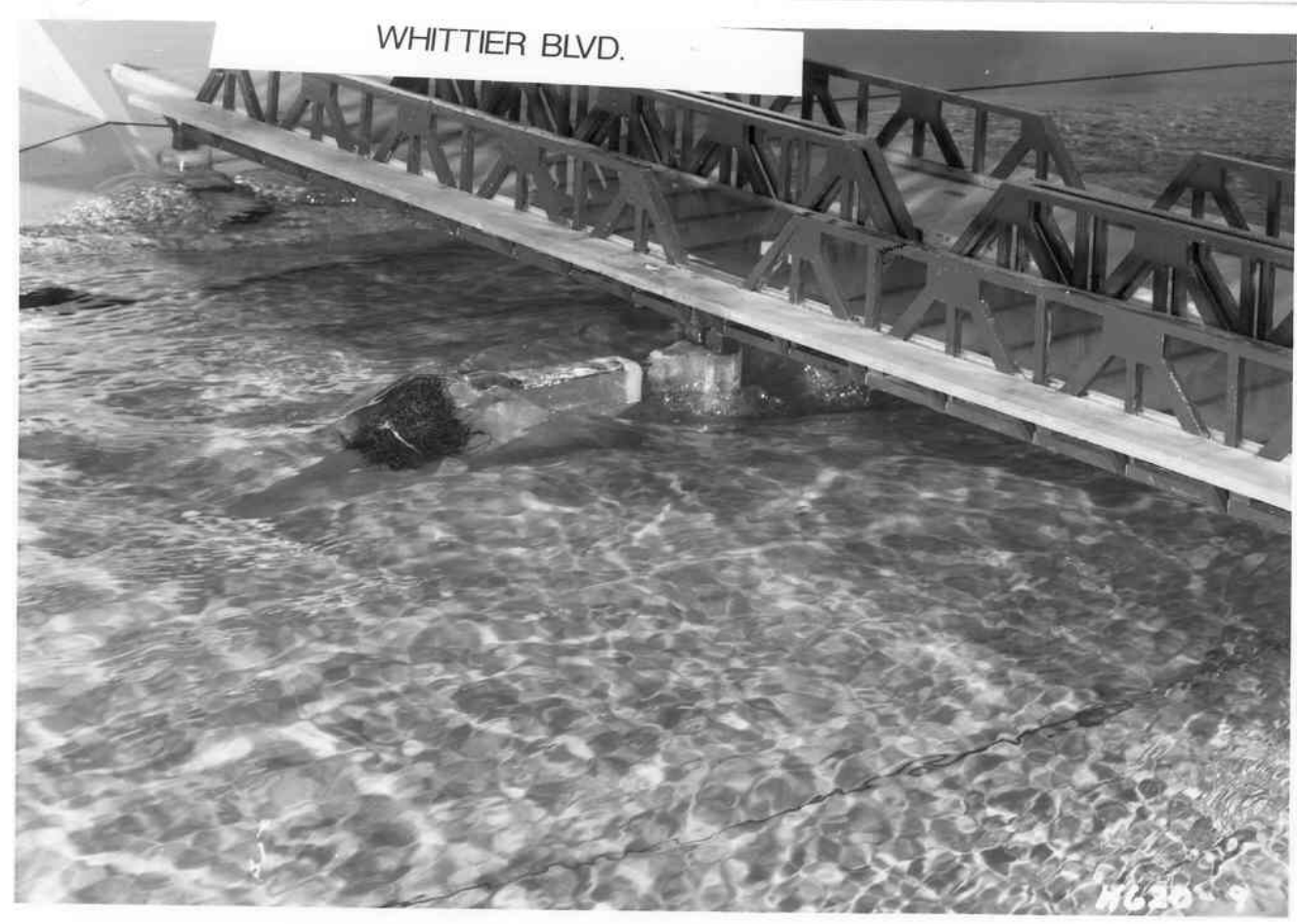

Figure 16. Flow conditions in 1:50-scale model of Rio Hondo River, debris on extended bridge pier. 


\section{Access Ramps}

The layout of maintenance access ramps is difficult in trapezoidal shaped channels. The CCRFCD's hydraulic design manual adequately describes layout of access ramps to rectangular channels, but trapezoidal channels are not as easily accessed. The difficulty lies in the fact that the ramps provide discontinuities in the flow boundaries and generate standing waves in the supercritical flow environment. Also, the width of the ramp must be allowed for in the channel design to provide adequate hydraulic capacity. The ramp's encroachment into the flow area can produce a choked flow condition. Acceptable design provides a roadway to the base of the channel that does not reduce the capacity of the channel or significantly raise the local water-surface elevation. 


\section{Transitions}

Geometrically complicated cross-section configurations are expensive to construct, because they required many concrete form changes. The longer the transition length, the more expensive the construction is. Also, local geometric constraints from utilities and rights of way constrain lengthy transitions of cross-sectional shape. Cross-section transitions include changes from trapezoidal to rectangular shapes (or vice versa) and width changes.

Ippen and Dawson (1951) demonstrate the applicability of the findings of Ippen (1951) to design problems of channel contractions, which is accomplished by comparing analytical solutions to laboratory data. These comparisons reveal that phase errors exist between the theoretical and observed depth profiles along a contraction. The theoretical waves are located upstream of the observed waves. Ippen and Dawson (1951) attribute this discrepancy to the hydrostatic pressure distribution assumption used in the analytical model. However, they note that the analytical solution is generally adequate for channel design purposes. They also provide design guidance for ways to reduce waves downstream of a contraction.

\section{Expansions}

Width expansions in channels conveying supercritical flow are subject to shock waves generated as the fan wave originating at the upstream end of the transition, intersects the downstream wall. Design guidance for geometric layout of supercritical flow in rectangular channels with increasing width is provided in EM 1110-2-1601 (Plate B-24) in terms of the approach Froude number and the expansion ratio (upstream width, $b_{1}$, to downstream width, $\mathrm{b}_{2}$ ). This guidance is based on the original work of Rouse et al. (1951).

Consideration is given by Rouse et al. (1951) for the design of channel expansions in the presence of supercritical flow. Their assumptions include hydrostatic pressure distribution, negligible friction losses, a horizontal channel, and vertical sidewalls. Rouse et al. (1951) provide graphical means for estimating the surface configuration of the negative wave generated at abrupt expansions and provide guidance for the design of efficient 
channel expansions, which eliminate disturbances at the downstream end of the transition.

Rouse et al. (1951), has been refined by Mazumder and Hager (1993). Mazumder and Hager (1993) determined that the Rouse reversed wall curve is too long for practical purposes. An expansion can be effectively underdesigned by applying a design approach Froude number of 2.5 times the values associated with design flow conditions. This produces a transition that is significantly shorter than that proposed by the original work of Rouse (1951). This underdesign procedure, which was validated with flume studies, results in a transition wall geometry that produces smooth flow expansions. The peak flow depths are determined from the relations of variables shown in Figure 17. Mazumder and Hager (1993) report that $h_{\mathrm{e}}=0.52 \mathrm{~h}_{1}, \mathrm{~h}_{\mathrm{M}}=\mathrm{h}_{\mathrm{w} 2}=0.6 \mathrm{~h}_{1}$, and $\mathrm{h}_{\mathrm{w} 1}=0.4 \mathrm{~h}_{1}$. The corresponding locations of maximum wall depths are $\mathrm{x}_{\mathrm{w} 1}=7.5 \mathrm{~b}_{1}$ and $\mathrm{x}_{\mathrm{w} 2}=14 \mathrm{~b}_{1}$. The maximum depth on the channel center line occurs at $x_{M}=9.5 b_{1}$.

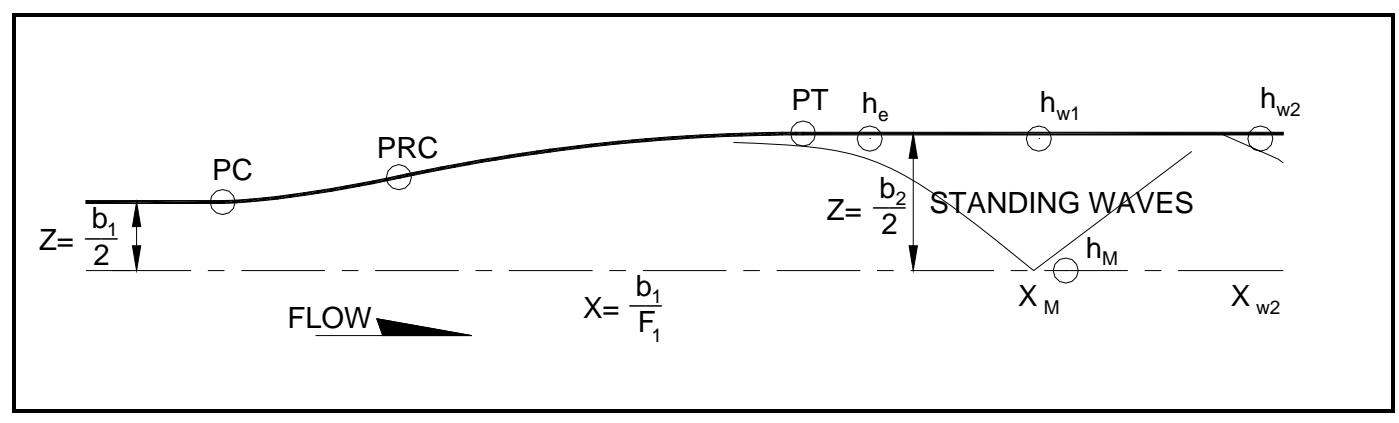

Figure 17. Half-plan sketch of expansion layout for supercritical flow.

\section{Contractions}

The Los Angeles County Flood Control District (1982) manual provides a good description for contractions in rectangular channels. This manual clearly describes the design process that provides the least disturbance waves downstream of the transition. The idea is to configure the geometry (transition length) so that the positive waves initiated at the upstream wall inset into the flow, intersect the downstream end of the transition (see Figure 18). This produces a negative shock that tends to cancel the positive wave thus producing a relatively uniform flow immediately downstream of the transition. The design procedure for these types of contractions is provided in EM 1110-2-1601. 


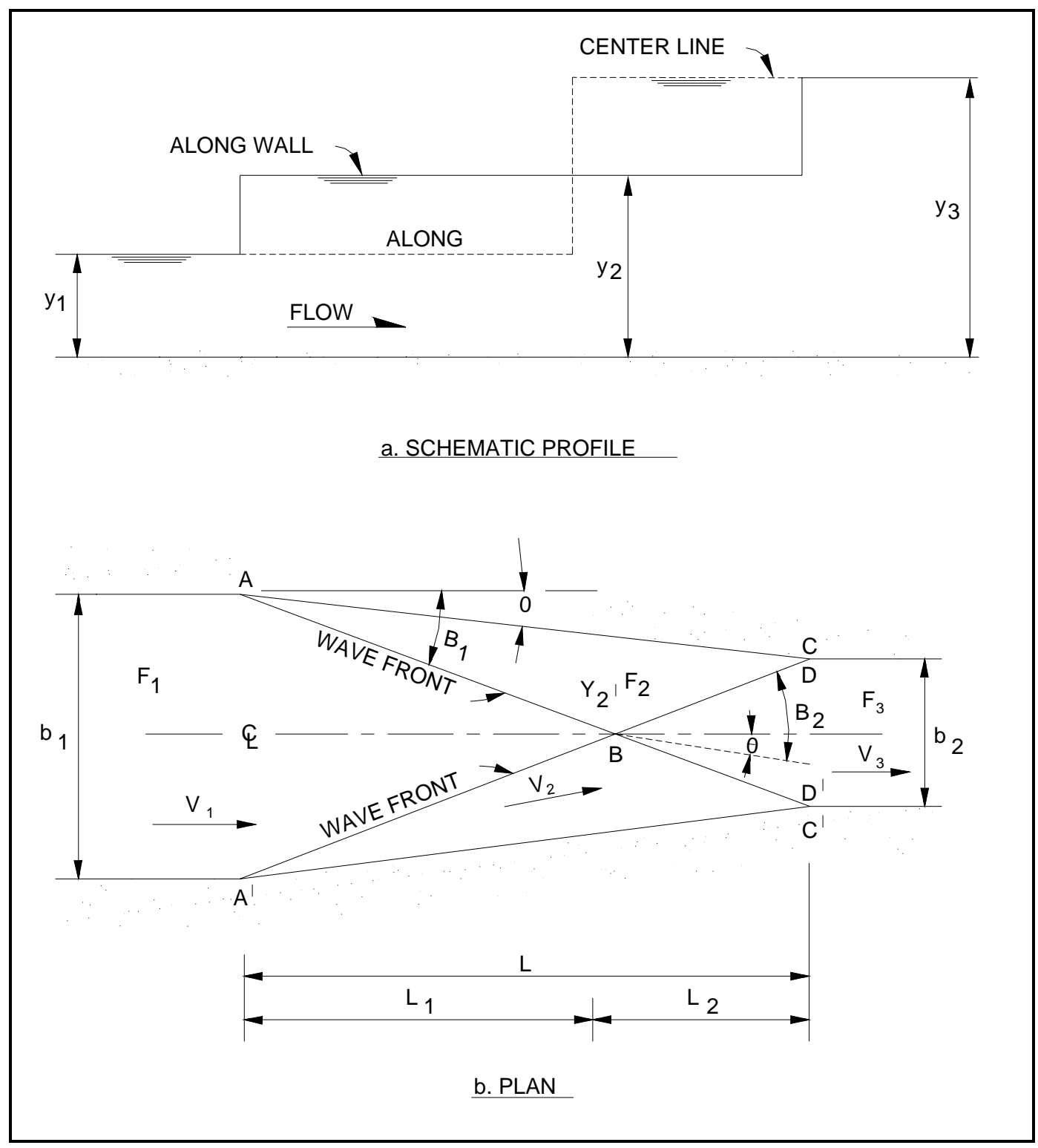

Figure 18. Supercritical flow contraction, rectangular channel.

\section{Sidewall Transitions}

Transitions between reaches having different cross-sectional shapes can generate shocks at points along the channel sidewalls where the boundary alignment changes. The three transition shapes described in EM 1110-21601 are the cylindrical quadrant, the warped, and the wedge types (Figure 19). The cylindrical transition works well in subcritical flow, but will produce standing waves when the flow is in the supercritical regime. Wedge-type transitions applied to supercritical flow generate standing waves at the point where the water surface intercepts change in flow direction. Warped type rectangular-to-trapezoidal and trapezoidal-to- 
rectangular transitions were found to provide a much smoother water surface on the Kahoma Stream Channel model study (George 1982) so that the channel was rectangular at bridge crossings. A typical trapezoidal-torectangular transition on the Kahoma Stream Channel is shown in Figure 20.

$\mathbb{E}$

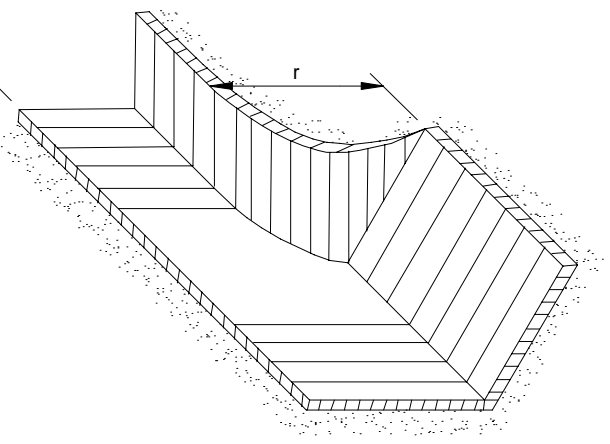

CYLINDRICAL QUADRANT

$\Psi$

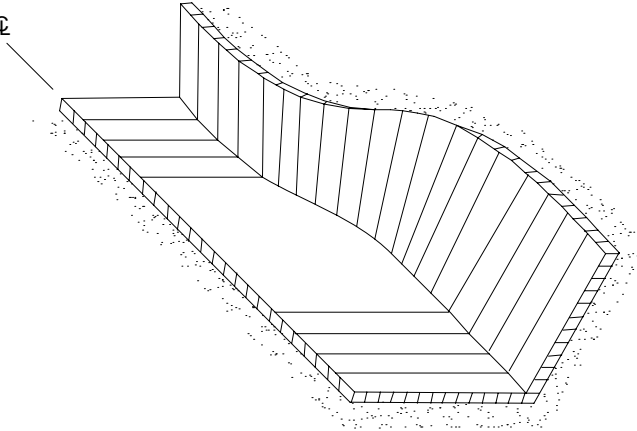

WARPED

$\mathbb{E}$

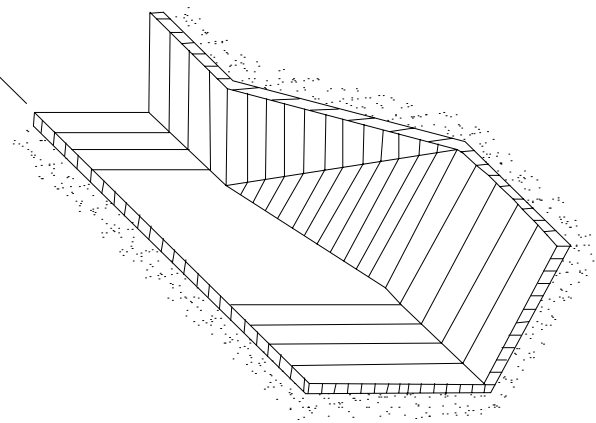

WEDGE

TRANSITION TYPES

Figure 19. Rectangular-to-trapezoidal transition types. 


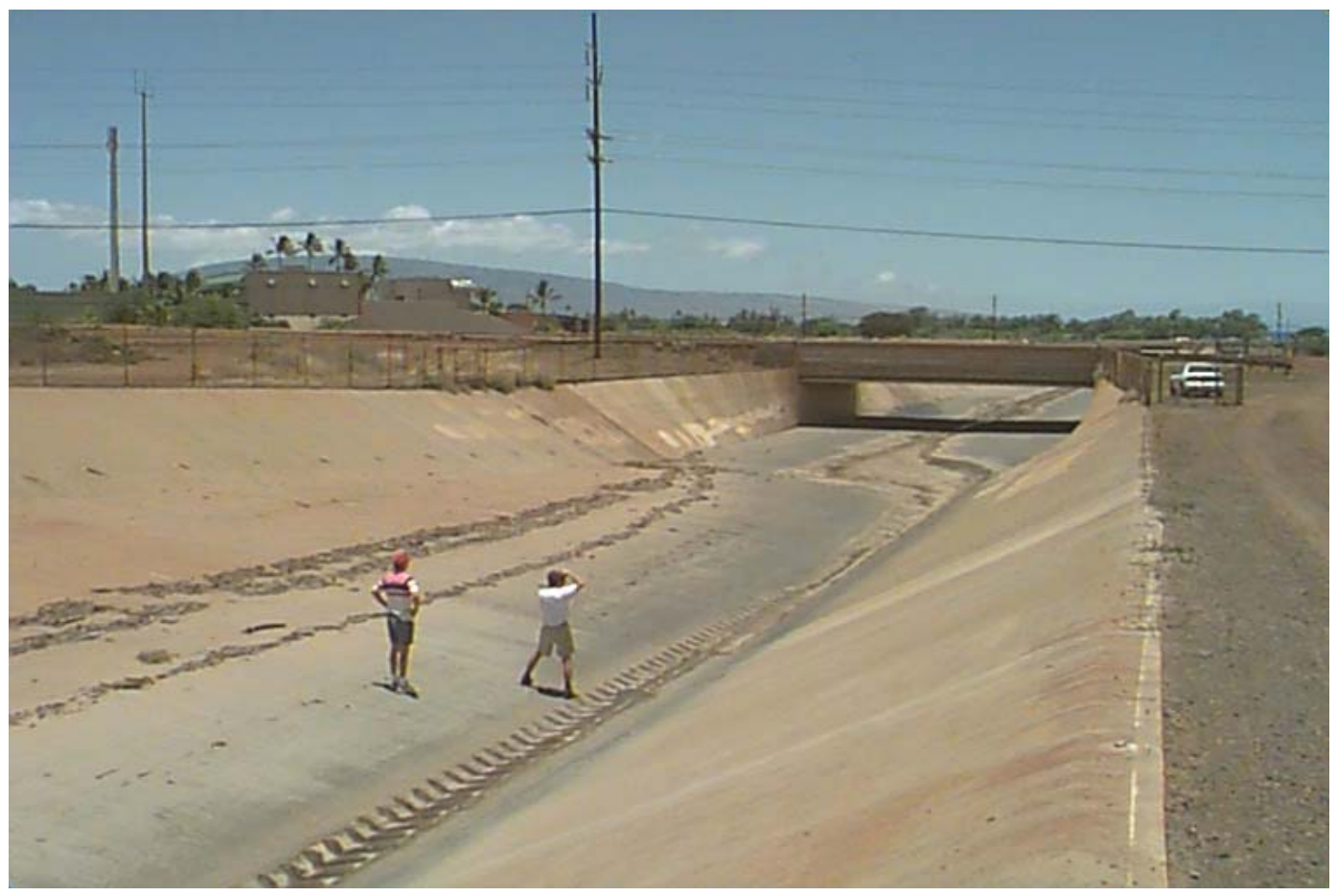

Figure 20. Trapezoidal (1V on 2H)-to-rectangular transition, Kahoma Stream Channel, Maui, HI. 


\section{Areas Requiring Additional Research}

This review has identified several common features of high-velocity channel flow that are deficient in terms of design guidance. These features include:

a. Supercritical confluences

- Trapezoidal channels

- Laterals from storm drains

b. Bridge piers

- Pier extensions

c. Access ramps

- Trapezoidal channels

Hydraulic design of the merging of two trapezoidal channels is not complete. From a hydraulic standpoint, the problem is associated in balancing the energy and momentum in an appropriate manner that the two flows combine without creating large shock waves that would require higher sidewalls to contain it. Geometrically, the problem is one of how the common sidewalls can be eliminated through the transition reach. Complicating the matter further is that the design must generally accommodate a range of flow ratios.

Another type of confluence is the case where culvert flow is introduced into the main channel by a lateral drain. These storm-water drains are usually located near roadway intersections where the rights of way are limited and the utilities are numerous which places constraints on geometric flexibility in routing the culverts.

Even if the culvert discharge is only 10 percent or less than the main channel flow, the momentum effects can produce significant bulking of the main channel flow. That is, the local main-channel water-surface elevation can be raised due to the introduction of lateral culvert flow. An understanding of the flow conditions in the vicinity of laterals is essential in the economic design of these structures. 
Access ramps constructed in trapezoidal shaped channels should be closely examined. The ramps can generate significant standing waves when the supercritical flow intersects them. General guidance as to size and shape relative to the trapezoidal channel size and discharge should be developed to facilitate the hydraulic design of these features. 


\section{Notations}

$$
\begin{aligned}
\mathrm{b} & =\text { bottom width of channel } \\
\mathrm{C} & =\text { constant for water-surface superelevation } \\
\mathrm{E} & =\text { specific energy } \\
\mathrm{e} & =\text { invert banking } \\
\mathrm{F}_{\mathrm{r}} & =\text { Froude number } \\
\mathrm{g} & =\text { gravitational acceleration } \\
\mathrm{h} & =\text { depth of flow } \\
\mathrm{h}_{\mathrm{c}} & =\text { critical depth of flow } \\
\mathrm{L}_{\mathrm{S}} & =\text { length of spiral } \\
\mathrm{Q} & =\text { total discharge } \\
\mathrm{q} & =\text { unit discharge }=\mathrm{Vh} \\
\mathrm{r} & =\text { radius of curvature } \\
\mathrm{TS} & =\text { tangent to spiral point } \\
\mathrm{SC} & =\text { Spiral to circular curve point } \\
\mathrm{CS} & =\text { Circular curve to spiral point } \\
\mathrm{ST} & =\text { spiral to tangent point } \\
\mathrm{V} & =\text { flow velocity } \\
\mathrm{W} & =\text { top width }
\end{aligned}
$$




\section{References}

American Association of State Highways and Transportation Officials (AASHTO). 1998. LRFD bridge design specifications. Second edition, 26-27.

Brater, E. F., and H. W. King. 1976. Handbook of hydraulics. New York: McGraw-Hill Book Co.

Clark County Regional Flood Control District. 1999. Hydrologic criteria and drainage design manual. Las Vegas, NV.

Federal Emergency Management Agency (FEMA). 1995. Engineering principles and practices for retrofitting floodprone residential buildings. FEMA Report No. 259. Washington, DC.

George, J. F. 1982. Kahoma Stream Channel Improvement Project, Maui, Hawaii, Hydraulic model investigation. Technical Report HL-82-19, Vicksburg, MS: U.S. Army Engineer Waterways Experiment Station,.

Haehnel, R. B. and S. F. Daly. 2002. Maximum impact force of woody debris on floodplain structures. Technical Report ERDC/CRREL TR-02-2, Hanover, NH: U.S. Army Engineer Research and Development Center.

Headquarters, U.S. Army Corps of Engineers. 1991. Hydraulic design of flood control channels. Engineer Manual No. 1110-2-1601, Washington, DC.

Henderson, F. M. 1966. Open channel flow. New York: MacMillian Publishing Co.

Hickerson, T. F. 1964. Routelocation and design. New York: McGraw-Hill Book Co.

Hite, J. E., S. E. Stonestreet, and M. E. Mulvihill. 1993. Model study of Rio Hondo Flood Control Channel, Los Angeles, California. ASCE Proceedings National Conference on Hydraulic Engineering, 1695-1700, San Francisco, CA.

Ippen, A. T. 1951. Mechanics of supercritical flow. Transactions of the American Society of Civil Engineers 116: 268-295.

Ippen, A. T., and J. H. Dawson. 1951. Design of channel contractions. Transactions of the American Society of Civil Engineers 116: 326-346.

Knapp, R. T. 1951. Design of channel curves for supercritical flow. Transactions of the American Society of Civil Engineers 116: 296-325.

Lenau, C. W. 1979. Supercritical flow in bends of trapezoidal section. J ournal of the Engineering Mechanics Division, Proceedings of the American Society of Civil Engineers 105(EM1): 43-54.

Los Angeles County Flood Control District. 1982. Design manual: Hydraulic. Los Angeles, CA: Los Angeles County Flood Control District. 
Mazumder, S. K. and W. H. Hager. 1993. Supercritical expansion flow in Rouse modified and reversed transitions. J ournal of Hydraulic Engineering 119(2): 201-219.

National Association of Australian State Road Authorities (NAASRA). 1990. Highway Bridge Design Specification. Australia.

National Research Council (U.S.) Highway Research Board. 1966. Highway drainage and scour studies; 3 reports, National Research Council. Publication 1365, Washington, DC.

Rice, C. E. 1985. Open channel junctions with supercritical flow. U.S. Department of Agriculture, Agriculture Research Service ARS-14.

Rouse, H. 1961. Fluid mechanics for hydraulic engineers. New York: Dover Publications Inc.

Rouse, H., B. V. Bhoota, and E. Hsu. 1951. Design of channel expansions. Transactions of the American Society of Civil Engineers 116: 347-363.

Schwalt, M., and W. H. Hager. 1995. Experiments to supercritical junction flow. Experiments in Fluids 18: 429-437.

Stonestreet, S. E. 1990. Critical flow through bridge piers in supercritical lined channels. M.S. thesis, California State University, at Long Beach, California.

Stonestreet, S. E., M. E. Mulvihill, and J. E. Hite, J. E. 1994. Revised hydraulic design of the Rio Hondo Flood Control Channel. ASCE Proceedings National Conference on Hydraulic Engineering, 401-405, Buffalo, NY.

U.S. Army Engineer District, Los Angeles. 1939. Report on engineering aspects, flood of March 1938; Appendix I, theoretical and observed bridge pier losses. Los Angeles, CA.

U.S. Army Engineer District, Los Angeles. 1972. Supercritical flow in curved channels; Hydraulic model investigation. Report No. 1-109, Los Angeles, CA.

U.S. Bureau of Reclamation. 1967. General design information for structures, Chapter 2, canals and related structures. In Design Standards No. 3. Denver, CO: U.S. Department of the Interior.

Woodward, S. M., and C. J. Posey. 1941. Hydraulics of steady flow in open channels. New York: Wiley and Sons, 112. 


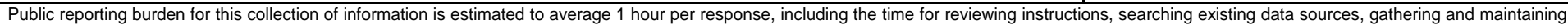

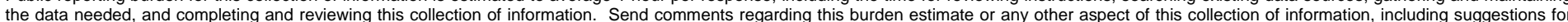

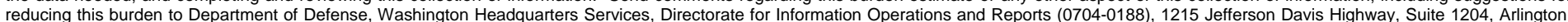

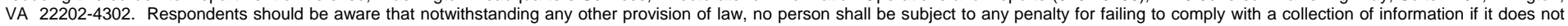
display a currently valid OMB control number. PLEASE DO NOT RETURN YOUR FORM TO THE ABOVE ADDRESS.
1. REPORT DATE (DD-MM-YYYY) July 2006

\section{TITLE AND SUBTITLE}

Hydraulic Design of Channels Conveying Supercritical Flow
3. DATES COVERED (From - To)

5a. CONTRACT NUMBER

5b. GRANT NUMBER

5c. PROGRAM ELEMENT NUMBER

5d. PROJECT NUMBER

5e. TASK NUMBER

5f. WORK UNIT NUMBER

8. PERFORMING ORGANIZATION REPORT NUMBER

ERDC/CHL TR-06-5

Coastal and Hydraulics Laboratory

U.S. Army Engineer Research and Development Center

3909 Halls Ferry Road

Vicksburg, MS 39180-6199

9. SPONSORING I MONITORING AGENCY NAME(S) AND ADDRESS(ES)

U.S. Army Corps of Engineers

Washington, DC 20314-1000
10. SPONSOR/MONITOR'S ACRONYM(S)

11. SPONSOR/MONITOR'S REPORT NUMBER(S)

\section{DISTRIBUTION I AVAILABILITY STATEMENT}

Approved for public release; distribution is unlimited.

\section{SUPPLEMENTARY NOTES}

\section{ABSTRACT}

This is a review of the Hydrologic Criteria and Drainage Design Manual (Clark County Regional Flood Control District 1999) of the Clark County Regional Flood Control District (CCRFCD). Areas of needed research relative to channels conveying supercritical flow and corresponding channel appurtenances have been identified.

The extension of features common to supercritical channel flow is presented. A case is made that extension of hydraulic design guidance of supercritical confluences (trapezoidal channels and laterals from storm drains), extensions to bridge piers, and access ramps for trapezoidal channels is needed.

\section{SUBJECT TERMS}

Clark County, Nevada

Flood-control channels

16. SECURITY CLASSIFICATION OF:

\section{a. REPORT}

Unclassified

\section{b. ABSTRACT}

Unclassified
Hydraulic design Supercritical flow

\begin{tabular}{l|c|}
$\begin{array}{l}\text { 17. LIMITATION } \\
\text { OF ABSTRACT }\end{array}$ & $\begin{array}{c}\text { 18. NUMBER } \\
\text { OF PAGES }\end{array}$ \\
& 38 \\
\hline
\end{tabular}

19a. NAME OF RESPONSIBLE PERSON

19b. TELEPHONE NUMBER (include area code) 